\title{
SELEÇÃO DE ISOLADOS DE FUNGOS ENTOMOPATOGÊNICOS PARA O CONTROLE DE Bemisia tabaci BIÓTIPO B
}

\section{ELIZABETH QUISBERTH RAMOS}

Engenheiro Agrônomo

Orientador: Prof. Dr. SÉRGIO BATISTA ALVES

Dissertação apresentada à Escola Superior de Agricultura "Luiz de Queiroz", Universidade de São Paulo, para obtenção do título de Mestre em Ciências, Área de Concentração: Entomologia.

PIRACICABA

Estado de São Paulo - Brasil

Outubro - 2001 


\section{Dados Internacionais de Catalogação na Publicação (CIP)}

DIVISÃO DE BIBLIOTECA E DOCUMENTAÇÃO - ESALO/USP

\section{Quisberth Ramos, Elizabeth}

Seleção de isolados de fungos entomopatogêncios para o controle de Bemisia tabaci Biótipo B / Elizabeth Quisberth Ramos. - - Piracicaba, 2001.

57 p. : il.

Dissertação (mestrado) - - Escola Superior de Agricultura Luiz de Queiroz, 2001. Bibliografia.

1. Controle biológico 2. Fungo entomopatogênico 3. Inseto-nocivo 4. Mosca branca I. Título

CDD

632.96

\section{"Permitida a cópia total ou parcial deste documento, desde que citada a fonte - O autor"}




\section{AGRADECIMENTOS}

Ao Prof. Sérgio Batista Alves pela orientação, estímulo, confiança e amizade.

Aos professores do curso de Pós-Graduação em Entomologia (ESALQ-USP), pelos valiosos ensinamentos e colaborações.

Ao Prof. Dr. Bonifácio Peixoto Magalhães por ter sido a primeira pessoa em Brasil a me incentivar na pesquisa e pela amizade.

À Coordenadoria de Aperfeiçoamento de Pessoal de Nível Superior (CAPES), pela bolsa de estudo que possibilitaram a execução desse trabalho.

Aos Drs. Clarice Demétrio e Silvano Cesar da Costa, pelo auxilio nas análise estatísticas.

Ao Prof. Dr. Evoneo Berti Filho, pela amizade e revisão do "summary".

À Rogério Biaggioni Lopes pelo incentivo, amizade e auxilio na redação do trabalho de dissertação.

Aos funcionários da Biblioteca da ESALQ-USP. 
Aos amigos do Laboratório de Patologia e Controle Microbiano de Insetos, Marco Antonio, Solange, Marcel, Luiz, Leonardo, Luciana, Ricardo, Marcelo, Marcos, Daniella, Adriana, Melissa e Ana pela amizade, compreensão e incentivo durante este tempo de convivência.

À Rita, Geni, Marilene e Fernando, pela amizade.

A todos os colegas do curso de Pós-Graduação em Entomologia, pelo companheirismo. 


\section{SUMÁRIO}

Página

LISTA DE FIGURAS....................................................................... vii

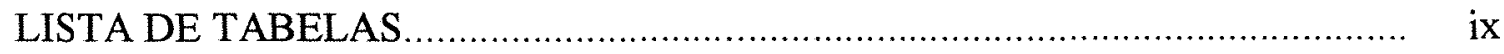

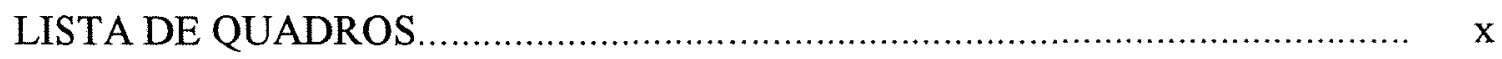

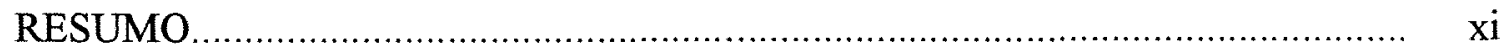

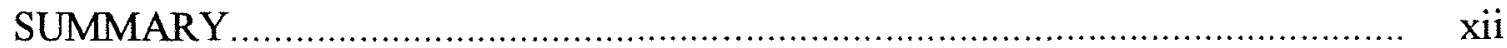

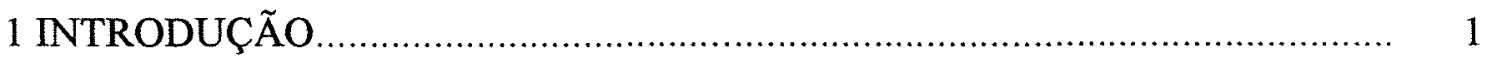

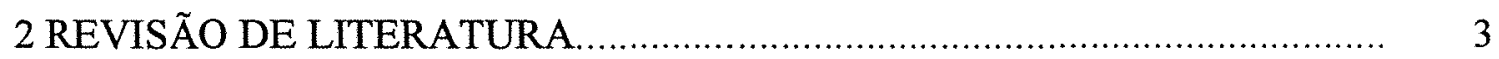

2.1 Bioecologia de Bemisia tabaci biótipo B............................................. 3

2.2 Danos causados por Bemisia tabaci biótipo B............................................ 5

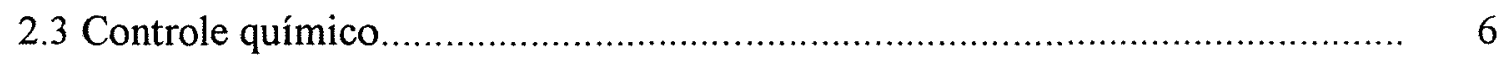

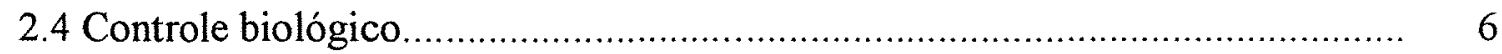

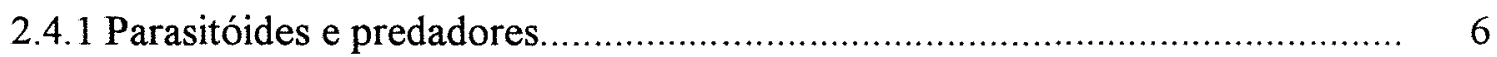

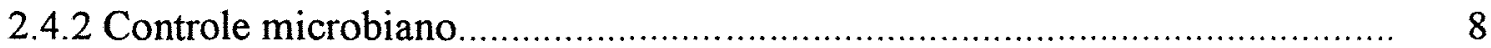

3 MATERIAL E MÉTODOS................................................................ 15

3.1 Criação e manutenção de Bemisia tabaci biótipo B em casa-de-vegetação...... 15

3.2 Seleção de isolados......................................................................... 16

3.2.1 Determinação da concentração de seleção para o isolado 447 de Beauveria

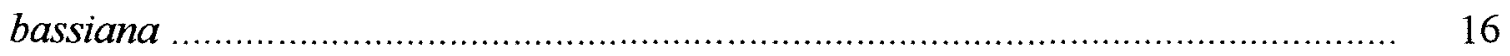

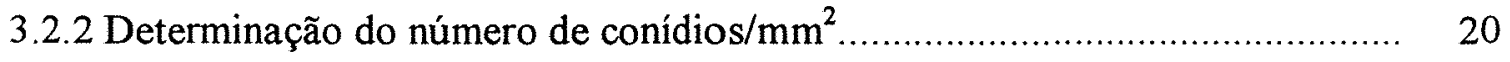

3.2.3 Seleção de isolados de fungos visando ao controle de Bemisia tabaci

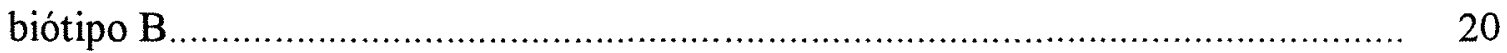

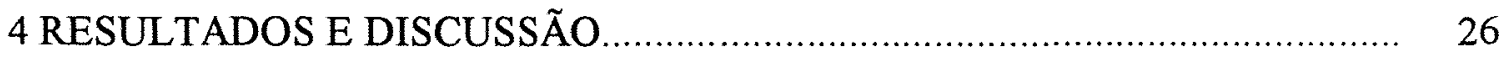

4.1 Criação e manutenção de Bemisia tabaci biótipo B em casa-de-vegetação...... 26

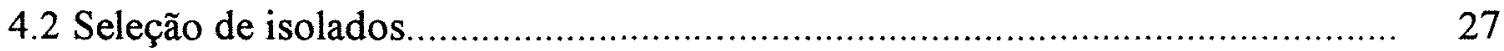


4.2.1 Determinação da Concentração de seleção para o isolado 447 de Beauveria bassiana.

4.2.2 Seleção de isolados de fungos visando ao controle de Bemisia tabaci biótipo $\mathrm{B}$. 29

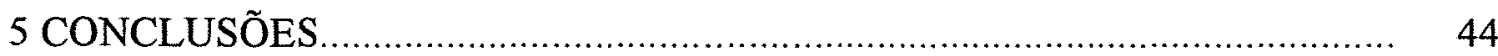

REFERÊNCIAS BIBLIOGRÁFICAS......................................................... 45 


\section{LISTA DE FIGURAS}

Página

1 a) Adultos de Bemisia tabaci biótipo B b) folhas infestadas com ovos, ninfas e adultos de mosca-branca c) vasos com plantas de soja d) manutenção da colônia (folhas de pepino).

2 a) Placas de Petri contendo folhas infestadas com ninfas de $3^{0}$ ínstar de Bemisia tabaci biótipo $\mathrm{B}$ b) placas de Petri incubando após a inoculação com os patógenos $\left(25 \pm 0,5^{\circ} \mathrm{C}, 80 \pm 5 \%\right.$ UR e 12 horas de fotofase).

3 Proporção de mortalidade de ninfas de $3^{0}$ ínstar de Bemisia tabaci biótipo B, cinco dias após a inoculação com Beauveria bassiana (447) a) valores observados e estimados b) gráfico meio-normal de dados observados em $10^{6}$, $5 \times 10^{6}, 10^{7}, 5 \times 10^{7}$ e $10^{8}$ conídios $/ \mathrm{mL}\left(25 \pm 0,5^{\circ} \mathrm{C}, 95 \pm 5 \%\right.$ UR e 12 horas de fotofase)

4 Ninfas de $3^{0}$ ínstar de Bemisia tabaci biótipo B com sintomas e sinais de Beauveria bassiana a) ninfa sadia e infectada b e c) coloração rosada causada pela oosporina e saída do fungo por aberturas naturais (orifício vasiforme e espiráculos) $50 \mathrm{x}$ e d) confirmação da mortalidade das ninfas em placas com ágar-água $(1,5 \%)$ a $25 \pm 0,5^{\circ} \mathrm{C}, 95 \pm 5 \%$ UR e 12 horas de fotofase.

5 Fases de desenvolvimento de Beauveria bassiana sobre ninfa de $3^{0}$ ínstar de Bemisia tabaci biótipo $\mathrm{B}$ a) adesão de conídios de Beauveria bassiana na cutícula, $12 \mathrm{~h}$ após a inoculação b) conídio com hifas de Beauveria bassiana na cutícula da ninfa c) colonização da cutícula e produção de conídios de Beauveria bassiana pelo orifício vasiforme após a colonização na hemocele da ninfa, $120 \mathrm{~h}(\mathrm{MEV})$. 
6 Mortalidade corrigida e confirmada de ninfas de $3^{0}$ instar de Bemisia tabaci biótipo $\mathrm{B}$ com fungos entomopatogênicos, cinco dias após a inoculação com fungos entomopatogênicos $\left(25 \pm 0,5^{\circ} \mathrm{C}, \quad 80 \pm 5 \%\right.$ UR e 12 horas de fotofase) 


\section{LISTA DE TABELAS}

Página

1 Identificação de isolados de fungos entomopatogênicos utilizados nos bioensaios de seleção, em ninfas de $3^{\underline{0}}$ ínstar de Bemisia tabaci biótipo $\mathrm{B}$

2 Deviances residuais do modelo binomial

3 Teste F para agrupamento de tratamentos e estimativa do fator de heterogeneidade.

4 Tratamentos agrupados

5 Valores observados de proporção de mortalidade de ninfas de $3^{0}$ instar de Bemisia tabaci biótipo $\mathrm{B}$, cinco dias após a inoculação com fungos entomopatogênicos $\quad\left(25 \pm 0,5^{\circ} \mathrm{C}, \quad 80 \pm 5 \% \quad\right.$ UR $\quad$ e 12 horas de fotofase) 


\section{LISTA DE QUADROS}

Página

1 Composição do meio de cultura Batata-Dextrose-Ágar (BDA) ......................... 24

2 Composição do meio de cultura Meio Completo (MC) ................................... 24 


\title{
SELEÇÃO DE FUNGOS ENTOMOPATOGÊNICOS PARA O CONTROLE DE Bemisia tabaci BIÓTIPO B
}

\author{
Autora: ELIZABETH QUISBERTH RAMOS \\ Orientador: Prof. Dr. SÉRGIO BATISTA ALVES
}

\section{RESUMO}

Em bioensaios de laboratório foram estudados isolados de Beauveria bassiana (25), Metarhizium anisopliae (7), Paecilomyces spp. (11) e Verticillium lecanii (1) visando ao controle microbiano de Bemisia tabaci biótipo B. A pesquisa foi realizada sob condições controladas $\left(25 \pm 0,5^{\circ} \mathrm{C}, 80 \pm 5 \%\right.$ UR e 12 horas de fotofase). Foram utilizadas folhas de soja infestadas com ninfas de $3^{0}$ instar, inoculadas com $2 \mathrm{~mL}(0,2$ $\mu \mathrm{l} / \mathrm{cm}^{2}$ ) de suspensões contendo $10^{7}$ conídios/mL aplicadas usando-se uma Torre de Potter ( 15 libras $\left./ \mathrm{pol}^{2}\right)$. Todos os isolados foram patogênicos para as ninfas, sendo que a maioria causou entre 10 a $40 \%$ de mortalidade. Os isolados mais patogênicos foram $B$. bassiana (447) e (969), M. anisopliae (1037), (816), (E9) e Paecilomyces spp. (CB144) com 57, 59, 61, 68, 89 e 48\% de mortalidade, respectivamente. Foi possível concluir que os isolados E9, 1037 e 816 de M. anisopliae e os isolados 447 e 969 de B. bassiana são promissores para o desenvolvimento de bioinseticidas para o controle de $B$. tabaci biótipo $\mathrm{B}$. 


\title{
SELECTION OF ENTOMOPATOGENIC FUNGI AGAINST Bemisia tabaci BIOTYPE B
}

\author{
Author: ELIZABETH QUISBERTH RAMOS \\ Adviser: Prof. Dr. SÉRGIO BATISTA ALVES
}

\section{SUMMARY}

Isolates of Beauveria bassiana (25), Metarhizium anisopliae (7), Paecilomyces spp. (11), and Verticillium lecanii (1) were evaluated for their pathogenicity against third-instar nymphs of Bemisia tabaci biotype B. The research was conducted under controlled conditions $\left(25 \pm 0,5^{\circ} \mathrm{C}, 80 \pm 5 \% \mathrm{RH}\right.$ and 12:12 L:D). Soybean leaves were treated with $2 \mathrm{~mL}$ of conidial suspentions $\left(10^{7}\right.$ conidia/mL) applied by using a Potter Tower $\left(15 \mathrm{lb} / \mathrm{pol}^{2}\right)$. All the isolates were pathogenic to nymphs and caused from 10 to $40 \%$ of mortality. The most pathogenic isolates were B. bassiana (447) and (969), $M$. anisopliae (1037), (816), (E9) and Paecilomyces spp. (CB144) causing 57, 59, 61, 68, 89 and $48 \%$ of mortality, respectively. The results indicate that E9, 1037 and 816 isolates of M. anisopliae and 447 and 969 isolates of $B$. bassiana are the most promising ones the development of bioinsecticide to control of silverleaf whitefly. 


\section{INTRODUÇÃo}

Bemisia tabaci (Genn.) é uma praga que se encontra amplamente distribuída nas regiões tropicais e subtropicais. Além da alta capacidade reprodutiva, esse inseto apresenta uma grande facilidade de dispersão e um elevado número de hospedeiros alternativos. Essas características, associadas ao desenvolvimento de linhagens resistentes a inseticidas têm favorecido o aumento acelerado de populações dessa praga.

$O$ inseto provoca perdas significativas de produção, tanto pelos danos diretos como indiretos. Os danos diretos são representados pela sucção de seiva e injeção de toxinas durante a alimentação, reduzindo o vigor da planta. Outro prejuizo de ordem direta é a deposição de "honeydew" na superficie das folhas, o que favorece a fumagina. Os danos indiretos são provocados pela transmissão do geminivírus, que induz anomalias fisiológicas na planta, prejudicando a produção.

Várias culturas têm sido afetadas de forma direta por B. tabaci na América Latina e Caribe nas últimas décadas. Esse fato levou a um abuso no uso dos inseticidas por parte dos agricultores, as vezes até com aplicações diárias. Em 1992 o "Centro Agronómico Tropical de Investigación y Enseñanza" (CATIE) promoveu um plano de ação para o manejo de mosca-branca e geminivírus na Costa Rica. No Brasil, Lourenção \& Nagai (1994) e França et al., (1996) observaram intensa colonização desse inseto sobre áreas cultivadas, nos Estados de São Paulo e Distrito Federal.

Atualmente, existem estudos para deteç̧ão, identificação e caracterização dos biótipos de Bemisia sp. com a utilização de marcadores moleculares. Essa técnica utiliza padrões de eletroforese de isoenzimas e RAPD-PCR, os quais demostram ser excelentes instrumentos para identificação e para a deteç̧ão de possíveis ocorrências de variações genéticas dentro das populações. 
O estudo da interação de inimigos naturais e $B$. tabaci pode ser efetivo na redução dessa praga. Dentre as táticas alternativas, agentes de controle biológico, representados por parasitóides, predadores e patógenos, são importantes para o manejo integrado da mosca-branca. A estratégia de utilização de fungos entomopatogênicos num programa de controle microbiano dessa praga envolve, como primeiro procedimento, a fase de seleção de isolados quanto à sua patogenicidade e virulência.

Estudos de seleção com os fungos Aschersonia aleyrodis, Paecilomyces fumosoroseus, Verticillium lecanii, Metarhizium anisopliae e Beauveria bassiana, agentes promissores de controle para esse grupo de insetos, são importantes para viabilizar o uso desses microrganismos no controle do complexo Bemisia spp. (Fransen, 1990b; Landa et al., 1994; Shannon, 1996; Alves, et al., 1998; Wraight et al., 2000).

$O$ objetivo desta pesquisa é selecionar isolados de fungos entomopatogênicos, altamente patogênicos para serem usados no controle de B. tabaci biótipo B. 


\section{REVISÃO DE LITERATURA}

\subsection{Bioecologia de Bemisia tabaci biótipo B}

Bemisia tabaci (Gennadius, 1889) (Hemiptera: Aleyrodidae) se caracteriza por possuir aparelho bucal tipo sugador labial tetraqueta, com canal de sucção e de saliva formados pela justaposição dos estiletes maxilares. $\mathrm{Na}$ fase adulta possuem quatro asas membranosas, recobertas com sustância pulverulenta branca, de onde vem o seu nome vulgar de "mosca-branca" (Carver et al., 1994).

Os aleirodídeos apresentam metamorfose incompleta, sendo observada uma grande variação na biologia de espécies dentro da mesma família. O ciclo de vida envolve, basicamente, uma fase de ovo, três ínstares ninfais ativos que se alimentam, seguidos de um quarto que é inativo. Esta fase é dividida em três estádios morfologicamente distintos, sendo usualmente o último referido como pupário. Após a quarta ecdise ocorre a emergência dos adultos (Byrne \& Bellows, 1991). Durante o período ninfal os insetos são achatados e finos, com formato elíptico. Somente no estágio de pupário têm formato convexo e um pouco mais volumoso. A diferenciação dos ínstares pode ser feita pela avaliação de outros caracteres morfológicos como tamanho e secreção de cêra (Caballero, 1996). A reprodução pode ser sexuada com oviparidade ou por partenogênese arrenótoca (Byrne \& Bellows, 1991).

Adultos e estágios imaturos de $B$. tabaci, geralmente, colonizam a face inferior das folhas de muitas plantas hospedeiras (Simmons, 1994; Caballero, 1996). Fatores relacionados às constantes práticas agrícolas, expansão do monocultivo, resistência de populações da mosca-branca a novos produtos fitossanitários, bem como o incremento no transporte mundial de plantas e produtos vegetais, provavelmente, têm provocado o 
aumento no número de hospedeiros alternativos de $B$. tabaci, o que a torna mais importante como praga (Brown \& Bird, 1992).

O conceito de biótipos ou raças proposto no ano de 1950 foi confirmado após a constatação de que, populações de insetos com parâmetros morfológicos semelhantes apresentavam diferenças nas características biológicas. Essas diferenças estavam relacionadas, principalmente, à ampla gama de hospedeiros, adaptação a planta hospedeira e capacidade de transmissão de virose (Bellows et al., 1994; Brown et al., 1995).

Atualmente, técnicas moleculares como eletroforese de isoenzimas (Perring et al., 1992) e RAPD-PCR (Gawel \& Bartlett, 1993) vêm sendo utilizadas para evidenciar as diferenças entre populações do inseto. No período de 1988 a 1991, estudos genéticos de reconhecimento por eletroforese, também foram usados como marcadores para diferenciar espécies e biótipos em populações de $B$. tabaci do Arizona, Califórnia, Flórida, Tennessee e Texas. Resultados indicaram a predominância do padrão B, também conhecido como $B$. argentifolii, o qual foi caracterizado pela sua capacidade de induzir a síndrome da folha prateada em Cucurbita spp. (Brown et al., 1995). Perring et al. (1992) também confirmaram a introdução do novo biótipo de B. tabaci na Califórnia.

O biótipo B de $B$. tabaci possui alta capacidade reprodutiva e facilidade de dispersão, quando comparado com populações previamente estabelecidas de outros biótipos (Bethke et al., 1991). Esses fatores, associados ao grande número de hospedeiros alternativos e ao desenvolvimento de linhagens resistentes a muitos inseticidas, têm favorecido o aumento acelerado de populações do inseto. Todas as características anteriormente descritas fazem com que o biótipo B apresente maior importância econômica.

No Brasil, por volta de 1992, Lourenção \& Nagai (1994) observaram intensa colonização desse biótipo em tomate, abóbora, brócolis, beringela, algodão, plantas ornamentais e plantas invasoras (Sida rhombifolia, Ipomea acuminata, Sonchus oleraceus e Solanum viarum) no estado de São Paulo. Desde esse período até o momento $B$. tabaci biótipo B já se disseminou por todo o país. Sua ação devastadora como praga e vetor de geminivírus tem provocado grande impacto na agricultura 
brasileira, ocasionando perdas de até $100 \%$ na produção de frutíferas, olerícolas, algodão e feijão, principalmente na região Nordeste.

\subsection{Danos causados por Bemisia tabaci biótipo B}

A praga é responsável por perdas significativas na produção das plantas hortícolas, feijão, soja, algodão, fumo, plantas ornamentais e ervas daninhas seja por danos diretos ou indiretos. Os danos diretos são representados pela sucção de seiva e injeção de toxinas durante a alimentação, reduzindo o vigor da planta, e pela deposição de "honeydew" na superficie das folhas, o que favorece o desenvolvimento do fungo Capnodium sp., sendo conhecido o sintoma como fumagina (Byrne $\&$ Bellows, 1991). A alimentação pela penetração dos estiletes intercelularmente faz com que os insetos adquiram o geminivírus que afeta tecidos vegetais associados ao floema (Brown $\&$ Bird, 1992; Costa, 1998). A transmissão de vírus (dano indireto) induz anomalias fisiológicas na planta, como o prateamento de folhas em cucurbitáceas e o amadurecimento irregular dos frutos em tomateiro (Brown et al., 1995).

Por ser um inseto de hábito polifago, a mosca-branca constitui problema grave para um grande número de cultivos de importância econômica como tomate, soja, melão, algodão, feijão, pepino, fumo e plantas ornamentais. Também coloniza várias espécies de ervas daninhas (Caballero, 1996). Um levantamento detalhado de plantas hospedeiras desse inseto foi realizado em 1986. Nesse trabalho, estimou-se que 74 famílias e 420 espécies de plantas podem ser atacadas pela praga. Com a recente introdução do biótipo $\mathrm{B}$, avaliou-se que esse número pode ultrapassar 500 espécies (Brown et al., 1995).

Os vírus do "Sub-group III Geminivirus" são transmitidos por aleirodídeos e na sua maioria por B. tabaci (Costa, 1998). As ninfas podem adquirir o vírus ao se alimentarem; porém seu hábito sedentário as impede de exercer um papel importante na transmissão. No entanto, os adultos são vetores eficientes desses fitopatógenos.

O período latente dos geminivírus "Euphorbia mosaic virus", "cotton leaf crumple virus", "bean golden mosaic virus", "tomato yellow leaf-curl virus" "tobacco 
leaf curl virus" e "squach leaf curl virus", foi de 20 horas ou mais. Esse intervalo pode refletir na eficiência de transmissão desses fitopatógenos por B. tabaci (Lastra, 1993; Costa, 1998).

\subsection{Controle químico}

O uso de produtos químicos é o método mais comum no controle da moscabranca, sendo os principais grupos de inseticidas utilizados os cloronicotinil, neonicotinoides, organofosforados, carbamatos, piretróides e piridil éter (Andrei, 1999). Entretanto, a falta de informações sobre o manejo desses produtos, e a característica dos danos ocasionados pelos insetos, têm feito com que os inseticidas sejam utilizados intensivamente. Isso tem provocado graves desequilíbrios no agroecosistema $\mathrm{e}$ favorecido a seleção de genótipos resistentes do inseto. Existem vários casos de resistência da mosca-branca a inseticidas, documentados em diferentes cultivos. De acordo com Carazo (1996) e Ortega-Arenas (1998) a seleção de linhagens resistentes está intimamente relacionada com o tempo de exposição da praga ao produto.

$\mathrm{O}$ uso inadequado e contínuo dos inseticidas não é a única solução para o controle da mosca-branca, no contexto do manejo integrado de pragas (MTP) sendo necessário o uso de inseticidas seletivos. Ambas as opções poderiam ser implementadas mediante a evolução de novos produtos, aperfeiçoamento dos métodos de aplicação e monitoramento constante dos níveis de resistência da mosca-branca, à fim de se determinar esquemas de rotação de inseticidas (Carazo, 1996).

\subsection{Controle biológico}

\subsubsection{Parasitóides e predadores}

$\mathrm{O}$ uso do controle biológico representa um procedimento importante no manejo do biótipo B de B. tabaci. Experiências com espécies de mosca-branca sugerem que esta tática é uma alternativa viável e pode ser utilizada em programas de manejo integrado da 
praga. Desde o início da década passada, o interesse pela utilização de inimigos naturais como agentes de controle biológico aumentou muito em diversos países da Europa, Estados Unidos e Canadá, sobretudo em cultivos protegidos comerciais (Fransen, 1990b; Brodsgaard, 1995; Gerling, 1996).

Fransen, 1990b relataram a existência de mais 30 espécies de inimigos naturais de $B$. tabaci entre coleópteros, dípteros, hemípteros, neurópteros e ácaros. Os predadores, geralmente, apresentam baixa eficiência de procura pela prêsa e têm ação restrita, já que para seu estabelecimento necessitam de alta densidade do hospedeiro. Atualmente, os predadores Delphastus pusillus e D. catalinae (Coleoptera:Coccinellidae) apresentam potencial de utilização na América Central e Estados Unidos, respectivamente (Cave, 1994; Heinz et al., 1999). Atualmente, Delphastus-System ${ }^{\circledast}$ a base da joaninha preta Delphastus pusillus é comercializado pela Biobest (Bélgica) e é recomendado para controlar mosca-branca (Biobest, 2001b).

Parasitóides como Encarsia sp. e Eretmocerus sp. (Hymenoptera: Aphelinidae) têm sido utilizados com sucesso no controle biológico da mosca-branca em casa-devegetação (Hoddle et al., 1998). Diversas espécies de parasitóides como E. nigricephala, E. pergandiella, E. quaintancei, E. strenua, E. formosa e Eretmocerus sp. foram encontradas parasitando, naturalmente, o complexo Bemisia sp., principalmente, em cultivos de Brassica spp., Brassica oleracea var. acephala, Cucurbita spp., Cucumis melo, Cucumis sativus, Lycopersicon esculentum e Euphorbia sp. em diversas regiões do mundo (VAN Lenteren, 1996; Ryley \& Ciomperlik, 1997; VAN Roermund, et al., 1997; Simmons \& Jackson, 2000; Viscarret et al.,2000).

Atualmente, a Koppert (Holanda) e Biobest (Bélgica) comercializam e recomendam produtos a base de parasitóides para o controle da mosca-branca como ENSTRIP $^{\circledast}$ (Encarsia formosa), ERCAL ${ }^{\circledast}$ (Eretmocerus eremicus), ENERMIX ${ }^{\circledast}$ (E. formosa + E. eremicus), Encarsia-System ${ }^{\otimes}$ (E. formosa) e Eretmocerus-System ${ }^{\circledR}$ (E. eremicus) (Biobest, 2001a; Koppert, 2001a).

Algumas alternativas de controle de aleirodídeos são importante como a associação entre inimigos naturais e produtos fitossanitários em concentrações subletais. Essas estratégias podem reduzir as populações dessa praga. Bethke \& Redak (1997) 
determinaram o efeito do imidacloroprid sobre adultos, estágios imaturos de $B$. argentifolii e o parasitismo por E. formosa em condições de casa-de-vegetação. Após 48 horas do tratamento com esse inseticida observou-se mais de $94 \%$ de mortalidade de adultos e estágios imaturos do inseto. De acordo com os autores, aplicações do imidacloroprid em baixa concentração é compatível com $E$. formosa para o controle de B. tabaci causando baixos níveis de mortalidade sobre esses parasitóides.

\section{4.2 Controle microbiano}

Complementando a ação dos parasitóides e predadores, os patógenos podem ser utilizados como importantes inimigos naturais de aleirodídeos. Esses patógenos pertencem a diferentes grupos, tais como vírus, bactérias, protozoários, rickétsias, fungos e nematóides. Ainda não se tem registros de nematóides parasitando moscabranca. É possivel que esses insetos sejam atacados por bactérias e vírus (Fransen, 1990b). Conforme Funk et al. (2001) o vírus denominado "Insect iridescent virus 6 " foi o primeiro encontrado em células de $B$. tabaci. O estabelecimento desse vírus infectando células da mosca-branca é um importante passo para futuros estudos sobre o uso de vírus contra esse inseto.

Os fungos entomopatogênicos são os organismos mais estudados e apresentam grande potencial para o controle de pragas (Fransen, 1990b). A ocorrência de fungos entomopatogênicos, em condições naturais, tanto enzoótica como epizooticamente, tem sido importante na redução das populações de pragas em agroecossistemas. A grande variabilidade genética desses entomopatógenos pode ser considerada uma das principais vantagens no controle microbiano de insetos. Cerca de $80 \%$ das doenças dos insetos têm como agentes etiológicos fungos pertencentes a 90 gêneros que reúnem 700 espécies distribuídas em diferentes grupos taxonômicos (Alves et al., 1998).

Os hifomicetos ocorrem em aleirodídeos causando infecção por penetração direta na cutícula em todos os estádios de desenvolvimento da mosca-branca. De forma geral, o desenvolvimento das micoses podem ser divididas em quatro fases: (1) adesão e germinação dos conídios sobre a cutícula dos insetos, (2) penetração na hemocele, (3) 
desenvolvimento do fungo, o qual geralmente resulta na morte do inseto e 4) reprodução que normalmente é assexuada originando grandes quantidades de conídios que se disseminam horizontalmente pelas culturas (Tanada \& Kaya, 1993; Shannon, 1996; Alves et al., 1998).

Os fungos entomopatogênicos que, freqüentemente, são isolados de aleirodídeos pertencem a mais de 20 espécies, incluindo Aschersonia aleyrodis Webber, Verticillium lecanii (Zimmerman) Viegas, Paecilomyces farinosus Brown \& Smith e $P$. fumosoroseus (Wise) Brown \& Smith e Beauveria bassiana (Balsamo) Vuillemin (Fransen, 1990b; Fransen, 1990a; Wraight et al., 2000). O fungo A. aleyrodis, é considerado o maior inimigo natural desses insetos em diversas regiões tropicais e subtropicais, sendo comuns a ocorrência de epizootias naturais (Fransen, 1990b). A infeção de A. aleyrodis a coccídeos e aleirodídeos já foi relatada por Ferron (1978) e Rombach \& Gillespie (1988). A. placenta controlou Dialeurodes citri na Caucásia e regiões do Mar Negro, causando $90 \%$ de mortalidade de ninfas sob condições favoráveis. Estudos da suscetibilidade de Trialeurodes vaporariorum à infecção por $A$. aleyrodis mostraram que cerca de $90 \%$ de ovos, ninfas de primeiro e segundo ínstar foram infectadas quando tratadas com $2 \mathrm{~mL}$ de uma suspensão de $4 \times 10^{6}$ conídios $/ \mathrm{mL}$. A porcentagem de infecção sobre o terceiro e quarto ínstar alcançou 76 e $28 \%$, respectivamente. Entretanto, adultos desses insetos não foram infectados por esse patógeno (Fransen et al., 1987).

Jà foi observada a ocorrência de $A$. aleyrodis sobre mosca-branca, em todas as regiões onde se cultivam citros no Brasil. O fungo ocorre sobre a fase imóvel de coccídeos e ninfas da mosca-branca, deixando os insetos com aparência róseoavermelhada. A época mais favorável às epizootias coincide com a maior precipitação pluviométrica. Assim, nas condições do Estado de São Paulo, o patógeno ocorre de novembro a fevereiro e nos estados do Nordeste, nos meses de maio a agosto. Para favorecer a disseminação desse fungo no pomares cítricos, recomenda-se a estratégia de aumento ou incremento, representada pelo corte de galhos com insetos atacados e a sua distribuição sobre árvores do pomar (Alves et al., 1998). 
Um dos inimigos naturais mais importantes de mosca-branca no mundo, é o fungo $P$. fumosoroseus considerado um dos patógenos mais promissores para seu controle (Lacey et al., 1996; Vidal et al., 1997). Essa espécie foi encontrada causando epizootias sobre Bemisia sp. e Trialeurodes sp., ambos em casa-de-vegetação e campo (Osborne \& Landa, 1992; Lacey et al., 1996; Vidal et al., 1997; Vidal et al., 1998). Esse patógeno infecta todos os estágios de desenvolvimento dos aleirodídeos, incluindo ovos (Landa et al., 1994).

Em ensaios de laboratório realizados por Vidal et al. (1997), 29 isolados de $P$. fumosoroseus causaram mortalidade variável de 68 a $94 \%$ em ninfas de segundo ínstar de $B$. argentifolii, as quais foram pulverizadas com $3,8 \times 10^{4}$ conídos $/ \mathrm{cm}^{2}$ usando a Torre de Potter. Resultados semelhantes foram encontrados por Vidal et al. (1998) que estudaram a infeção por $P$. fumosoroseus sobre ninfas de terceiro ínstar dessa mesma espécie em condições favoráveis de casa-de-vegetação $\left(23\right.$ e $32^{\circ} \mathrm{C} ; 73$ e $100 \%$ UR). Os autores utilizaram $5 \times 10^{4}$ conídos $/ \mathrm{cm}^{2}$, obtendo mortalidade de 70 e $80 \%$ após 7 e 14 dias da pulverização, respectivamente. Todos os cadáveres com sintomas de infeç̧ão (85\%) foram incubados em câmara úmida, sendo confirmada a presença do patógeno. Osborne et al. (1990) testaram a patogenicidade de P. fumosoroseus para ninfas de $B$. tabaci. Esses mesmos autores mencionaram que o fungo provocou mais de $90 \%$ de mortalidade após 72 horas da pulverização com $10^{6}$ conídios $/ \mathrm{mL}$, em condições de $27^{\circ} \mathrm{C}$ e $100 \%$ UR.

Foram realizados experimentos em laboratório visando determinar a velocidade de crescimento e desenvolvimento de $P$. fomosoroseus sobre o quarto ínstar de $B$. argentifolii. Avaliou-se o crescimento e desenvolvimento do fungo a $30^{\circ} \mathrm{C}$ e $100 \%$ UR. A colonização do hospedeiro por esse fungo ocorreu em 48 horas e o início da esporulação em 72 horas. Esses valores diminuíram quando os insetos foram mantidos a $20^{\circ} \mathrm{C}$, completando em 168 horas o ciclo do fungo. Com relação a UR, verificou-se que a germinação do fungo ocorreu às 168 e 12 horas, nas umidades de 85 a $100 \%$ UR, respectivamente. A $80 \%$ UR, não foi observado desenvolvimento do patógeno. A elevada flutuação da UR nas primeiras 24 horas após a pulverização pode diminuir o desenvolvimento do fungo (Landa et al., 1994). 
Vega et al. (1999) avaliaram a germinação de conídios e blastóporos de $P$. fumosoroseus sobre a cutícula $B$. argentifolii (ninfa de terceiro ínstar) e verificaram que os blastósporos germinaram, significativamente, mais rápido às duas, quatro, oito e 24 horas com 15, 37, 43 e 96\% de germinação, respectivamente. A germinação dos conídios ocorreu decorridas oito e 24 horas, com 31 e $99 \%$, respectivamente. Os autores sugeriram que o uso de blastósporos como ingrediente ativo na formulação é vantajoso em relação aos conídios.

Resultados encontrados por Osborne et al. (1990) e Osborne \& Landa (1992) demostraram que os índices de mortalidade causados por $P$. fumosoroseus foram maiores que àqueles provocados por $V$. lecanii e $B$. bassiana.

No México, o produto comercial Pae-Sin ${ }^{\bigotimes}$ a base de conídios de $P$. fumosoroseus, comercializado pela empresa Agrobiologicos de Nordeste S.A., é recomendado para aplicação em casa-de-vegetação e campo para o controle da "mosquita blanca" (Torres \& Cardénas, 1996). Um produto similar, Bemisin ${ }^{\circledR}$ tem sido comercializado pela Probioagro, S.A. de Acaragua, Venezuela para o controle de aleirodídeos.

Atualmente os micoinseticidas a base de conídios de $P$. fumosoroseus comercializados contra a mosca-branca nos Estados Unidos e Europa são os isolados denominados Pfr 97 e PreFeral WG ${ }^{(}$(Apoka 97), respectivamente. BotaniGard 22WP ${ }^{\circledR}$,

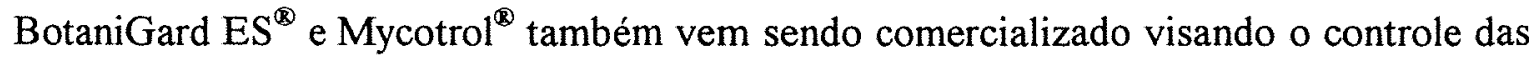
três importantes pragas de estufas (mosca-branca, tripes e afideos). Esses micoinseticidas são altamente seletivos e seguros para a maioria dos insetos benéficos, sendo excelentes para serem utilizados em programas de MIP (Landa et al., 1994; Biobest, 2001c; Mycotech, 2001a; Mycotech, 2001b ).

O fungo $V$. lecanii pode ocasionar epizootias de grande magnitude em regiões de clima tropical e subtropical, e em zonas temperadas, numa ampla gama de hospedeiros em insetos das Ordens Hemiptera, Coleoptera e Diptera (Mier et al., 1991). Segundo Fransen (1990b), esse fungo infecta ninfas e adultos de B. tabaci, não sendo patogênico para ovos. 
De acordo com Ekbom (1981), o fungo $V$. lecanii depende de alta umidade (aproximadamente 100\%) para causar infecção em aleirodídeos. São necessárias no mínimo 16 horas de alta unidade para se obter significativa porcentagem de mortalidade ocasionada por esse patógeno, com um ótimo de 20 horas. Ensaios realizados por Mier et al. (1991) avaliaram a patogenicidade do fungo sobre diferentes estágios de $T$. vaporariorum, mostrando que os maiores níveis de infecção ocorreram sobre ninfas de segundo ínstar. Resultados semelhantes foram obtidos por Garcia-Gonzálves \& LópezÁvila (1997). Hall et al. (1994) relataram que ninfas de primeiro ínstar de B. argentifolii não foram infectadas por $V$. lecanii. Entretanto, Meade and Byrne (1991) não encontraram diferenças significativas quanto a suscetibilidade ao patógeno com relação a idade ou espécies desses insetos. Os mesmos autores comprovaram infeção do primeiro e terceiro ínstar de $B$. argentifolii e $T$. vaporariorum. A velocidade de infeção dos ovos de ambas espécies foi extremamente baixa. Testes envolvendo a patogenicidade também foram realizados por Landa et al. (1994), com as espécies $V$. lecanii e $B$. bassiana, observando-se resultados promissores desses patógenos no controle de $B$. argentifolii quando pulverizados com $10^{7}$ conídios $/ \mathrm{mL}$.

Conforme Milner \& Lutton (1986) e Gillespie \& Claydon (1989), produtos a base de $V$. lecanii foram produzidos comercialmente com o nome de Mycotal $^{\circledR} \mathrm{e}$ Vertalec $^{\circledR}$ para o controle de aleirodídeos e afideos, respectivamente, desde 1982. Atualmente, o Mycotal ${ }^{\circledR}$ formulado com Verticillium lecanii-m é comercializado pela Koppert (Holanda) e recomendado para o controle da mosca-branca, afideos e tripes (Koppert, 2001b).

No Brasil, no Estado do Maranhão, Lourenção et al. (2001) relataram a ocorrência epizoótica de $V$. lecanii em campo, sobre ninfas de diferentes estágios de $B$. tabaci biótipo $\mathrm{B}$, reduzindo as populações desse inseto a níveis extremamente baixos em período chuvoso.

O fungo $B$. bassiana é um dos fungos mais estudados e usados no mundo (Wraight et al., 2000). Estágios ninfais de $B$. tabaci são muito susceptíveis a $B$. bassiana, apesar desse patógeno não ser considerado um importante inimigo natural da praga (Wraight et al., 1998; Zaki, 1998). Ramos et al. (2000) determinaram 62\% de 
mortalidade, quando foram inoculadas suspensões de $10^{8}$ conídios $/ \mathrm{mL}$ de $B$. bassiana sobre ninfas de primeiro ínstar, sendo os ovos não susceptíveis a esse patógeno. Vicentini et al. (2001) selecionaram isolados dessa espécie de fungo sobre ninfas de primeiro ínstar de B. tabaci biótipo B. Após sete dias da inoculação, os valores de mortalidade média alcançaram $25,7 \%$, variando de 6,1 a $92,3 \%$ depois de 14 dias da pulverização.

Em testes de laboratório utilizando $B$. bassiana e $P$. fumosoroseus Wraight et al. (2000) mostraram a patogenicidade desses fungos, em ninfas de terceiro ínstar de $B$. tabaci biótipo B. Observou-se $35 \%$ de mortalidade quando os insetos foram inoculados com $1 \mathrm{~mL}$ da suspensão concentrada $\left(10^{7}\right.$ conídios $\left./ \mathrm{mL}\right)$ equivalente a $0,6-1,4 \times 10^{3}$ conídios $/ \mathrm{mm}^{2}$ e incubados a $25 \%$ UR, $23 \pm 2{ }^{\circ} \mathrm{C}, 16$ horas de fotofase. Os mesmos autores realizaram ensaios em campo com aplicações de 4 a 5 dias de intervalo, onde foram utilizados isolados de $B$. bassiana e $P$. fumosoroseus $\left(5 \times 10^{13}\right.$ conídios $\left./ \mathrm{mL}\right)$ em $180 \mathrm{~L}$ água/ha ou 1 a $2,5 \times 10^{3}$ conídios $/ \mathrm{mm}^{2}$ e os dados de mortalidade superaram $90 \%$ para terceiro e quarto ínstar das ninfas. A concentração usada pelos autores representa cerca de $220 \mathrm{~g}$ de conídios puros por hectare, o que torna econômico o controle com esses fungos.

Diversas raças de Metarhizium anisopliae vêm sendo estudadas para o controle de insetos das Ordens Isoptera, Orthoptera, Hemiptera e Coleoptera que atacam culturas de importância econômica. Os estudos se referem, principalmente, a var. anisopliae, devido a sua considerável produção de destruxinas (Kershaw et al., 1999). Acredita-se que esse patógeno ocorra naturalmente sobre mais de 300 espécies de insetos das diferentes ordens, e que se apresenta como sendo um eficiente agente de controle biológico de insetos pragas (Zimmermann, 1993; Alves et al., 1998). Desde $1970 \mathrm{M}$. anisopliae vem sendo usado comercialmente no Brasil para o controle biológico de Manaharva posticata em cana-de-açucar (Alves et al., 1986; Gillespie \& Claydon, 1989; Zimmermann, 1993).

Experimentos de laboratório com fungos entomopatogênicos para o controle de ninfas de terceiro ínstar de $B$. tabaci mostraram que cinco isolados de $M$. anisopliae 
apresentaram altos níveis de virulência, sendo que somente um isolado alcançou $97 \%$ de mortalidade quando inoculados a uma concentração de $10^{7}$ conídios $/ \mathrm{mL}$ (Herrera, 1995).

Relatos de infeção por fungos da Ordem Entomophthorales são raramente encontrados na literatura sobre aleirodídeos (Lacey et al., 1996). No entanto, Gindin \& Bem-Ze'ev (1994) constataram que adultos de B. tabaci são mais suscetíveis do que as ninfas, quando inoculados com 60 conídios $/ \mathrm{mm}^{2}$ de Conidiobolus coronatus e causaram $95 \%$ de mortalidade sobre os adultos de esse inseto.

As grandes infestações de aleirodídeos são freqüentemente associadas com colônias de fungos escuros (Capnodium spp., Limacinia spp. e outros da família Capnodiaceae). Em situações de desenvolvimento intenso, esses fungos podem causar a morte de ninfas da mosca-branca. Alem, disso é comum encontrar outras espécies de entomopatógenos e fungos saprofiticos sobre Bemisia, como Acremonium sp., Aphanocladium album, Aspergillus sp., Cladosporium sp. Fusarium spp., Hirsutela sp. e Trichothecium reseum. Porém, existem poucas informações sobre a atividade patogênica desses fungos (Lacey et al., 1996).

O desenvolvimento de micoinseticidas para o controle de aleirodídeos requer cuidados especiais. A seleção de isolados é uma fase essencial para se iniciar um programa de controle microbiano. Outras características importantes que devem ser levadas em consideração para obter sucesso na utilização desses microrganismos são: eficiente produção massal, técnicas adequadas de aplicação, formulações e uso do melhoramento genético. Aplicações simultâneas de fungos com outros agentes de controle biológico ou produtos fitossanitários seletivos, podem ser realizadas com o objetivo de se obter maior sucesso no controle das diferentes espécies de aleirodídeos (Heale, 1988; Fransen, 1990a; Fransen, 1990b; Hilje, 1998). 


\section{MATERIAL E MÉTODOS}

O presente trabalho foi desenvolvido no Laboratório de Patologia e Controle Microbiano de Insetos, do Departamento de Entomologia, Fitopatologia e Zoologia Agrícola da Escola Superior de Agricultura "Luiz de Queiroz", Universidade de São Paulo (ESALQ-USP), em Piracicaba-SP, no período de janeiro de 2000 a fevereiro de 2001.

\subsection{Criação e manutenção de Bemisia tabaci biótipo $\mathrm{B}$ em casa-de-vegetação}

Na fase inicial, plantas de soja, (Glycine $\max$ L.) (Dicotiledonea: Fabaceae), infestadas com ovos e ninfas de B. tabaci biótipo B foram transportadas do Instituto Agronômico de Campinas (IAC) para uma casa-de-vegetação do setor de Patologia de Insetos da ESALQ-USP, para constituição da colônia estoque ( Figura la e 1b). Para a manutenção da colônia, foram utilizadas plantas de soja var. BRS157-LS25, tomate (Lycopersicon esculentum Miller), feijão (Phaseolus vulgaris L.), pepino (Cucumis melo L.), repolho (Brassica oleracea var. Capitata de Condolle), couve-flor (Brassica oleraceae var. Botrytis) e abóbora(Cucurbita pepo L.) (Figura 1d). Essas plantas foram cultivadas em vasos plásticos de $30 \times 40 \mathrm{~cm}$ contendo uma mistura de terra, areia e esterco bovino numa proporção de 1:1:1. Foram semeadas dez sementes por vaso e após a emergência das plântulas foram selecionadas as cinco mais vigorosas. Essas plantas foram mantidas, usando procedimentos físicos, isentas de pragas e doenças. As plantas com 15 a 20 dias de idade, foram transferidas para a casa-de-vegetação para infestação pelo inseto (Figura 1c). As plantas velhas e secas foram substituídas a cada 30 dias a fim de manter as condições ideais para uma boa multiplicação dos insetos. 


\subsection{Seleção de isolados}

\subsubsection{Determinação da concentração de seleção para o isolado 447 de Beauveria}

bassiana

Foram realizados testes preliminares para se determinar a concentração (conídios $/ \mathrm{mL}$ ) a ser utilizada na seleção dos fungos promissores para o controle da mosca-branca. Nessa etapa, utilizou-se um isolado padrão do Laboratório de Patologia e Controle Microbiano de Insetos, registrado no banco de patógenos como Beauveria bassiana isolado 447, obtido de Solenopsis invicta (Hymenoptera: Formicidae) em Cuiabá-MT, 1986 e armazenado a $-4^{\circ} \mathrm{C}$ em forma de conídios secos e puros. Para isso, foram preparadas suspensões de conídios desse isolado em água destilada esterilizada + $0,2 \mu \mathrm{l} /$ litro do espalhante adesivo (Tween $20^{\circledR}$ ) nas concentrações de $10^{6}, 5 \times 10^{6}, 10^{7}, 5$ $\times 10^{7}$ e $10^{8}$ conídios $/ \mathrm{mL}$. Para os testes, foram usadas folhas de plantas de soja infestadas com ninfas de $3^{0}$ ínstar de $B$. tabaci. A abscisão das folhas foi realizada com auxílio de bisturi deixando-se $5 \mathrm{~cm}$ de pecíolo, o qual foi envolvido com algodão umedecido em água destilada, evitando dessa forma o ressecamento precoce do material vegetal (Figura 2a). Cada folha, infestada com ninfas, foi transferida para placas de Petri $(15 \times 2 \mathrm{~cm})$ contendo uma camada de papel de filtro circular no fundo. Identificou-se as ninfas de $3^{0}$ ínstar marcando-as ao redor com tinta tipo resina PVA colorida e preservante (Helios Carbex S.A.) com auxilio de pincel fino. Para cada tratamento, foram preparadas cinco repetições. Foram selecionadas, ao acaso, 20 ninfas/folha para cada repetição, totalizando 100 insetos para cada tratamento. As placas, contendo os insetos, foram transferidas para câmara climatizada tipo BOD (Biological Oxygen Demand) a $25 \pm 1^{\circ} \mathrm{C}$, $80 \pm 5 \%$ UR e 12 horas de fotofase, e molhadas diariamente para evitar o ressecamento precoce da folha, mantendo-se assim a umidade do ambiente e qualidade do substrato alimentar (Figura $2 \mathrm{~b}$ e $2 \mathrm{c}$ ). As placas contendo as ninfas foram acondicionadas em BOD, 24 horas antes da inoculação, para evitar o estresse dos insetos. As pulverizações foram realizadas com Torre de Potter (Burkard Manufacturing Co. Ltd.), calibrada a 15 libras/pol ${ }^{2}$ de pressão, utilizando-se alíquotas de $2 \mathrm{~mL}\left(0,2 \mu \mathrm{l} / \mathrm{cm}^{2}\right)$ da suspensão 
preparada com $10^{7}$ conídios $/ \mathrm{mL}$. As avaliações foram realizadas diariamente, até o quinto dia após inoculação, registrando-se a mortalidade diária de ninfas em cada folha. Para a confirmação da morte das ninfas pelo patógeno, os cadáveres foram lavados em álcool $70 \%$, colocados sobre papel de filtro esterilizado e posteriormente transferidos para placas plásticas de Petri de 9 × 1,5 cm contendo ágar-água (1,5\%) para favorecer o crescimento e esporulação do fungo após 24 horas (Figura 4d). Essas placas foram mantidas em condições de $25 \pm 0,5^{\circ} \mathrm{C}, 80 \pm 5 \%$ UR e 12 horas de fotofase segundo a metodologia de Wraight et al. (1998). Após os testes preliminares foi selecionada a concentração que ocasionou mortalidade de ninfas superior a $50 \%$ até o quinto dia após a inoculação. 

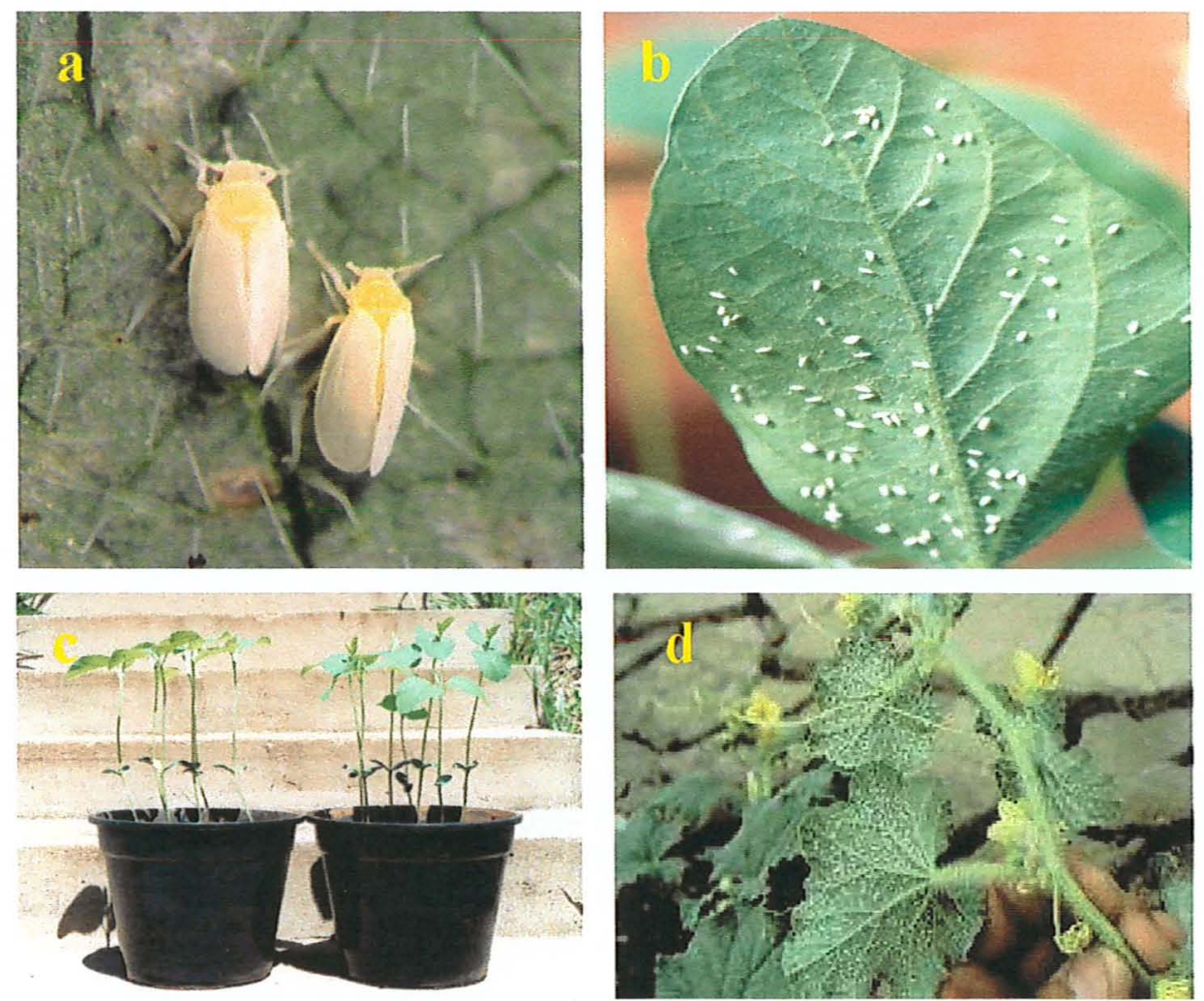

Figura 1 - a) Adultos de Bemisia tabaci biótipo B b) folhas infestadas com ovos, ninfas e adultos de mosca-branca c) vasos com plantas de soja d) manutenção da colônia (folhas de pepino). 

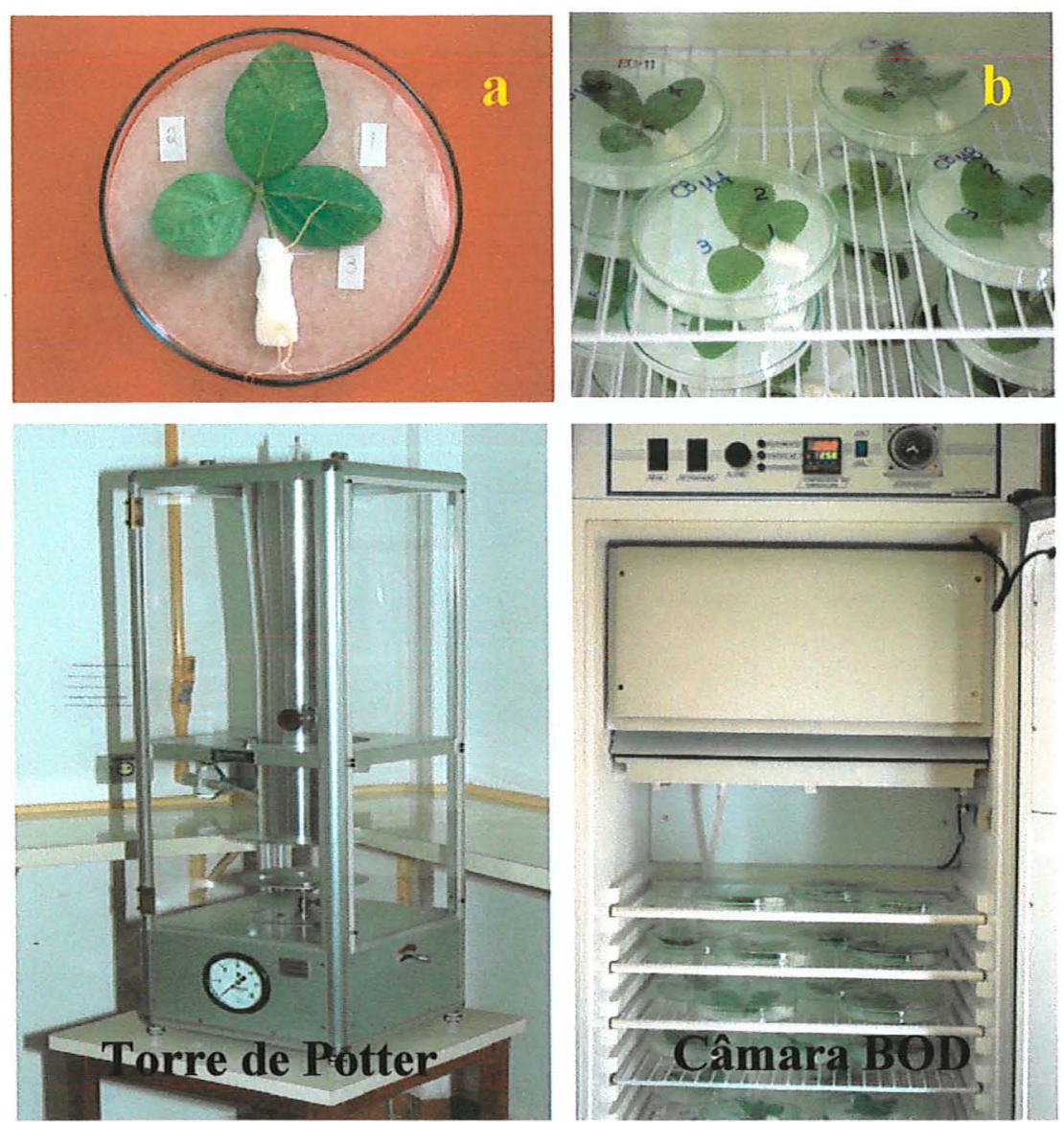

Figura 2 - a) Placas de Petri contendo folhas infestadas com ninfas de $3^{0}$ ínstar de Bemisia tabaci biótipo B b) placas de Petri incubando após a inoculação com os patógenos $\left(25 \pm 0,5^{\circ} \mathrm{C}, 80 \pm 5 \%\right.$ UR e 12 horas de fotofase). 


\subsubsection{Determinação do número de conídios $/ \mathrm{mm}^{2}$}

Após os testes preliminares de determinação da concentração padrão, foram feitos bioensaios de pulverização, para o controle de ninfas de $3^{0}$ instar de $B$. tabaci. Para determinar o número de conídios $/ \mathrm{mm}^{2}$, foi utilizado o isolado 447 de $B$. bassiana descrito no item 4.2.1. Nessa etapa, inicialmente preparou-se uma suspensão contendo $10^{7}$ conídios/mL e pulverizou-se $2 \mathrm{~mL}$ desta suspensão conidial sobre a câmara de Neubauer usando-se a Torre de Potter (Burkard Manufacturing Co. Ltd.), calibrada a 15 libras/pol ${ }^{2}$ de pressão. Após a pulverização, a câmara foi colocada em capela de fluxo laminar para secagem. Em seguida, colocou-se sobre sua superficie a lamínula e procedeu-se a contagem dos conídios. Para facilitar a observação dos conídios eles foram corados com azul de metileno. Após a contagem, a média do número de conídios foi transformada de acordo com $\mathrm{n} \times 10^{-4}$ onde " $\mathrm{n}$ " é igual ao número médio de esporos contados e $10^{-4}$ corresponde ao fator de conversão para o campo utilizado, uma vez que a lamínula, sendo colocada a $0,100 \mathrm{~mm}$ de altura, proporciona o volume de $10^{-4} \mathrm{~mL}$ no campo de $1 \mathrm{~mm}^{2}$. Para cada campo foram feitas três repetições.

\subsubsection{Seleção de isolados de fungos visando ao controle de Bemisia tabaci biótipo B}

Nos bioensaios de seleção dos fungos visando o controle de $B$. tabaci, foram utilizados 25 isolados de Beauveria sp., 11 de Paecilomyces spp., 1 de Verticillium lecanii e 7 de Metarhizium anisopliae, procedentes de insetos e solos coletados em diferentes Estados do Brasil e Bolívia (Tabela 1). Os isolados encontram-se armazenados no banco de entomopatógenos do Laboratório de Patologia. 
Tabela 1. Identificação de isolados de fungos entomopatogênicos utilizados nos bioensaios de seleção, em ninfas de $3^{0}$ ínstar de Bemisia tabaci biótipo $\mathrm{B}$.

\begin{tabular}{ccc}
\hline Espécies/Isolado & $\begin{array}{c}\text { Substrato ou Inseto } \\
\text { Hospedeiro }\end{array}$ & Local e Data de Origem \\
&
\end{tabular}

Paecilomyces fumosoroseus

1200 (ESALQ-USP) $^{*}$

Mahanarva posticata

Bahia, 1996

Paecilomyces lilacinus

1145 (ESALQ-USP)

Sarcina sp.

São Paulo, 1994

1125 (ESALQ-USP)

Solo

Espirito Santo, 1993

623 (ESALQ-USP)

Solo

Mato Grosso, 1987

Paecilomyces sp.

CB130 (IB-SP) ${ }^{* *}$

Solo

São Paulo, 1999

CB148 (IB-SP)

Solo cana-de-açucar

São Paulo, 2001

CB144 (IB-SP)

Solo

Paraná, 2001

CB114 (IB-SP)

Solo

São Paulo, 1998

CB139 (IB-SP)

Solo

São Paulo, 2001

1232 (ESALQ-USP)

Lagria villosa

São Paulo, 1998

1253 (ESALQ-USP)

Lagria villosa

São Paulo, 1999

Beauveria bassiana

$447^{* * * *}$ (ESALQ-USP)

Solenopsis invicta

Mato Grosso, 1986

$1255^{* * *}$ (UAGRM)

Lagria villosa

SCZ-Bolívia, 1998

1195 (ESALQ-USP)

Solo

Mato Grosso, 1996

1246 (ESALQ-USP)

Sarcina sp.

São Paulo, 1999

1248 (ESALQ-USP)

Hemiptera-Auchenorrhyncha São Paulo, 1999 
Tabela 1. Identificação de isolados de fungos entomopatogênicos utilizados nos bioensaios de seleção, em ninfas de $3^{0}$ ínstar de Bemisia tabaci biótipo B.

\begin{tabular}{|c|c|c|}
\hline Espécies/Isolado & $\begin{array}{l}\text { Substrato ou Inseto } \\
\text { Hospedeiro }\end{array}$ & Local e Data de Origem \\
\hline 1202 ESALQ-USP) & Blatella germanica & São Paulo, 1996 \\
\hline 1197 (ESALQ-USP) & Solo & Mato Grosso, 1996 \\
\hline 1249 (ESALQ-USP) & Phasmatodea & São Paulo, 1999 \\
\hline 1261 (ESALQ-USP) & Coleoptera & São Paulo, 2000 \\
\hline 1250 (ESALQ-USP) & Coleoptera & São Paulo, 1999 \\
\hline 1252 (ESALQ-USP) & Coleoptera & São Paulo, 1999 \\
\hline PL61 (ESALQ-USP) & Cosmopolites sordidus & Espirito Santo, 1992 \\
\hline PL63 (ESALQ-USP) & Atta sp. & São Paulo, 1992 \\
\hline 1210 (ESALQ-USP) & Indeterminado & São Paulo, 1997 \\
\hline 1219 (ESALQ-USP) & Coleoptera & São Paulo, 1998 \\
\hline 1211 (ESALQ-USP) & Coccinellidae & São Paulo, 1997 \\
\hline 1213 (ESALQ-USP) & Plutella sp. & São Paulo, 1997 \\
\hline 1245 (ESALQ-USP) & Coccinellidae & São Paulo, 1999 \\
\hline 1240 (ESALQ-USP) & Tingidae & São Paulo, 1999 \\
\hline 1208 (ESALQ-USP) & Cigarrinha do citros & São Paulo, 1997 \\
\hline 1207 (ESALQ-USP) & Dalbulus maidis & São Paulo, 1997 \\
\hline 969 (ESALQ-USP) & Blatella germanica & São Paulo, 1990 \\
\hline \multicolumn{3}{|l|}{ Beauveria sp. } \\
\hline 1233 (ESALQ-USP) & Crisomellidae & São Paulo, 1998 \\
\hline 908 (ESALQ-USP) & Solenopsis sp. & Mato Grosso, 1989 \\
\hline
\end{tabular}


Tabela 1. Identificação de isolados de fungos entomopatogênicos utilizados nos bioensaios de seleção, em ninfas de $3^{0}$ ínstar de Bemisia tabaci biótipo B.

\begin{tabular}{lll}
\hline \multicolumn{1}{c}{ Espécies/Isolado } & \multicolumn{1}{c}{$\begin{array}{c}\text { Substrato ou Inseto } \\
\text { Hospedeiro }\end{array}$} & Local e Data de Origem \\
\hline 868 (ESALQ-USP) & Formicidae & Goiás, 1989 \\
Verticillium lecanii & & \\
972 & Coccus viridis & São Paulo, 1990 \\
Metarhizium anisopliae & & \\
E9 (ESALQ-USP) & Mahanarva posticata & Pernambuco, 1981 \\
1037 (ESALQ-USP) & Solenopsis sp. & Rio Grande do Sul, 1992 \\
1104 (ESALQ-USP) & Solo & Piauí, 1992 \\
PL43 (ESALQ-USP) & Mahanarva posticata & Alagoas, 1981 \\
816 (ESALQ-USP) & Solo & São Paulo, 1988 \\
935 (ESALQ-USP) & Diatraea saccharalis & Bahia, 1990 \\
866 (ESALQ-USP) & Atta sp. & Goiás, 1989 \\
\hline
\end{tabular}

ESALQ-USP, Escola Superior de Agricultura "Luiz de Queiroz" Universidade de São Paulo " IB-SP Instituto Biológico de São Paulo

*...UAGRM Universidad Autónoma "Gabriel René Moreno" (I.I."El Vallecito") Santa Cruz, Bolívia

**** Isolado padrão

A repicagem e multiplicação de cada isolado foi feita em placas de Petri contendo meio de cultura BDA (batata + dextrose + ágar) ou MC (meio completo), onde foram semeados os conídios com alça de platina e posteriormente espalhados com alça de Drigalski. A composição dos meios de cultura para a produção dos isolados encontrase nas Quadro 1 e 2. 


\begin{tabular}{|cc|}
\hline Ingredientes & Quantidade \\
\hline Ágar & $20,0 \mathrm{~g}$ \\
Dextrosol & $15,0 \mathrm{~g}$ \\
Batata * & $200,0 \mathrm{~g}$ \\
$\begin{array}{c}\text { Streptomicina } \\
\text { (antibiótico) }\end{array}$ & $0,5 \mathrm{~g}$ \\
$\mathrm{H}_{2}$ O Destilada & $1000 \mathrm{~mL}$ \\
\hline
\end{tabular}

* Solanum tuberosum (L.)

Meio esterilizado em autoclave por 20 minutos a $120^{\circ} \mathrm{C}$

Quadro 1 - Composição do meio de cultura Batata-Dextrose-Ágar (BDA).

\begin{tabular}{|cc|}
\hline Ingredientes & Quantidade \\
\hline Fosfato de potássio & $0,36 \mathrm{~g}$ \\
Fosfato de sódio & $1,05 \mathrm{~g}$ \\
Sulfato de magnésio & $0,6 \mathrm{~g}$ \\
Cloreto de potássio & $1,0 \mathrm{~g}$ \\
Glucose & $10,0 \mathrm{~g}$ \\
Nitrato de sódio & $1,58 \mathrm{~g}$ \\
Extrato de levedura & $5,0 \mathrm{~g}$ \\
Ágar & $20,0 \mathrm{~g}$ \\
$\mathrm{H}_{2} \mathrm{O}$ Destilada & $1000 \mathrm{Ml}$ \\
\hline
\end{tabular}

Meio esterilizado em autoclave por 20 minutos a $120^{\circ} \mathrm{C}$

Quadro 2 - Composição do meio de cultura Meio Completo (MC) 
Após a repicagem dos isolados, as placas foram transferidas para câmara climatizada tipo $\mathrm{BOD}$ a $25 \pm 0,5^{\circ} \mathrm{C}$ e 12 horas de fotofase, onde foram mantidas por um período de 10 dias. Posteriormente, para preparar as suspensões para os bioensaios, as placas foram raspadas com auxílio de uma espátula para a retirada dos conídios, os quais foram transferidos para tubos de vidro contendo água estéril com $0,2 \mu 1 /$ litro de espalhante adesivo (Tween $20^{\circledR}$ ). Para cada bioensaio foram realizadas avaliações de viabilidade e contagem de conídios em câmara de Neubauer. A suspensão foi padronizada para $10^{7}$ conídios $/ \mathrm{mL}$, concentração determinada anteriormente. O acondicionamento das placas com as ninfas foi similar ao descrito no item 3.2.1. A seleção dos isolados promissores foi feita em função da patogenicidade do fungo sendo selecionados aqueles que causaram mortalidade superior a $80 \%$. O protocolo utilizado nos experimentos foi semelhante, em alguns parâmetros, aos adotados por Landa et al., (1994), Herrera, (1995) e Wraight et al. (1998).

Os dados obtidos foram analisados usando-se um modelo de regressão binomial (Nelder \& Wedderburn, 1972) no programa SAS - Statistical Analysis System $(\mathrm{P}<0,05)$. O cálculo da correção de mortalidade foi realizado utilizando a fórmula de Abbott (1925). 


\section{RESULTADOS E DISCUSSÃo}

\subsection{Criação e manutenção de Bemisia tabaci biótipo B em casa-de-vegetação}

A mosca-branca B. tabaci biótipo B desenvolve-se em plantas de soja, tomate, feijão, pepino, repolho, couve-flor e abóbora, sendo que adultos desse inseto abrigavamse e ovipositam, preferentemente, na face inferior das folhas das plantas, onde são encontrados simultaneamente ovos, ninfas, pupários e adultos. Entretanto, todas as fases de desenvolvimento de $B$. tabaci são encontradas em maior número em plantas novas de soja. A medida que aumenta a população de ninfas, as folhas de soja apresentam cor amarelada devido à alimentação tornando-se menos atrativas aos adultos.

A grande vantagem da criação em plantas da soja em relação às demais espécies utilizadas foi a capacidade de manter altas populações do inseto. Por isso, foi necessário introduzir constantemente plantas novas. A maior desvantagem foi a presença freqüente de Oidio sp., durante o período de abril a agosto, apesar de ter sido utilizada uma variedade resistente (BRS157-LS25). Esta doença provocou a queda das folhas, muitas das quais contendo colônias de ninfas. Nesse período foi intensificado o plantio das outras espécies de plantas, que não foram afetadas por esse fitopatógeno e assim permitiram a multiplicação do inseto. A diminuição do inóculo de Oidio sp. foi feito colocando-se as plantas infestadas distantes das novas, descartando as plantas severamente doentes, irrigando a região do colo da planta e diminuindo a umidade relativa na estufa pelo controle do sistema de refrigeração. Não foram feitas aplicações de fungicidas químicos porque seus resíduos poderiam prejudicar a eficiência das aplicações dos entomopatógenos nos bioensaios.

$\mathrm{Na}$ colônia estoque foi observada a ocorrência natural de Delphastus (Coleoptera: Coccinellidae) e Encarsia sp. (Hymenoptera: Aphelinidae), predando e 
parasitando ninfas de $B$. tabaci, respectivamente. Esses insetos benéficos são considerados eficientes na redução da população da mosca-branca em casa-de-vegetação e campo, sendo inclusive comercializados na Europa e América do Norte para o controle de B. tabaci (Ryley \& Ciomperlik, 1997; Heinz et al., 1999; Simmons \& Jackson, 2000; Biobest, 2001a; Biobest, 2001b; Koppert, 2001a).

Outros insetos comuns observados na colônia de $B$. tabaci foram os tripes, que se alimentavam das plantas tornando-as menos adequadas às moscas-brancas e, ocasionalmente, predando ninfas desse inseto. Assim, para a supressão tanto de inimigos naturais e tripes, diariamente esses insetos eram retirados com um pincel, sendo também eliminadas as folhas contendo ninfas parasitadas. Dessa maneira, promoveu-se o controle parcial de suas populações sem comprometer a criação.

\subsection{Seleção de isolados}

\subsubsection{Determinação da concentração de seleção para o isolado 447 de Beauveria bassiana}

O modelo logístico padrão ajustado às proporções de mortalidade das ninfas, referentes às concentrações de $10^{6}, 5 \times 10^{6}, 10^{7}, 5 \times 10^{7}$ e $10^{8}$ conídios $/ \mathrm{mL}$, apresentou "deviance" de 1016,4335 com 88 graus de liberdade (g.1.), mostrando clara evidência de superdispersão. Usando-se o gráfico do tipo meio-normal com envelope simulado (Hinde \& Demétrio, 1997), foi possível ver que o modelo logístico linear com fator de heterogeneidade ajusta-se bem aos dados, conforme mostra a Figura 3a.

$O$ valor da estatística $F$ para teste do efeito linear de $\log$ (concentração) no modelo logístico com superdispersão foi igual a 138,87, sendo significativo ao nível de $5 \%$ de probabilidade. A proporção esperada de ninfas mortas pode ser calculada usandose a seguinte equação $\hat{p}_{i}=\frac{\exp \{-4,6864+0,6146 \log (\text { conc })\}}{1+\exp \{-4,6864+0,6146 \log (\text { conc })\}}$. A Figura $3 b$ mostra os valores observados e a curva estimada para a proporção de ninfas mortas. 


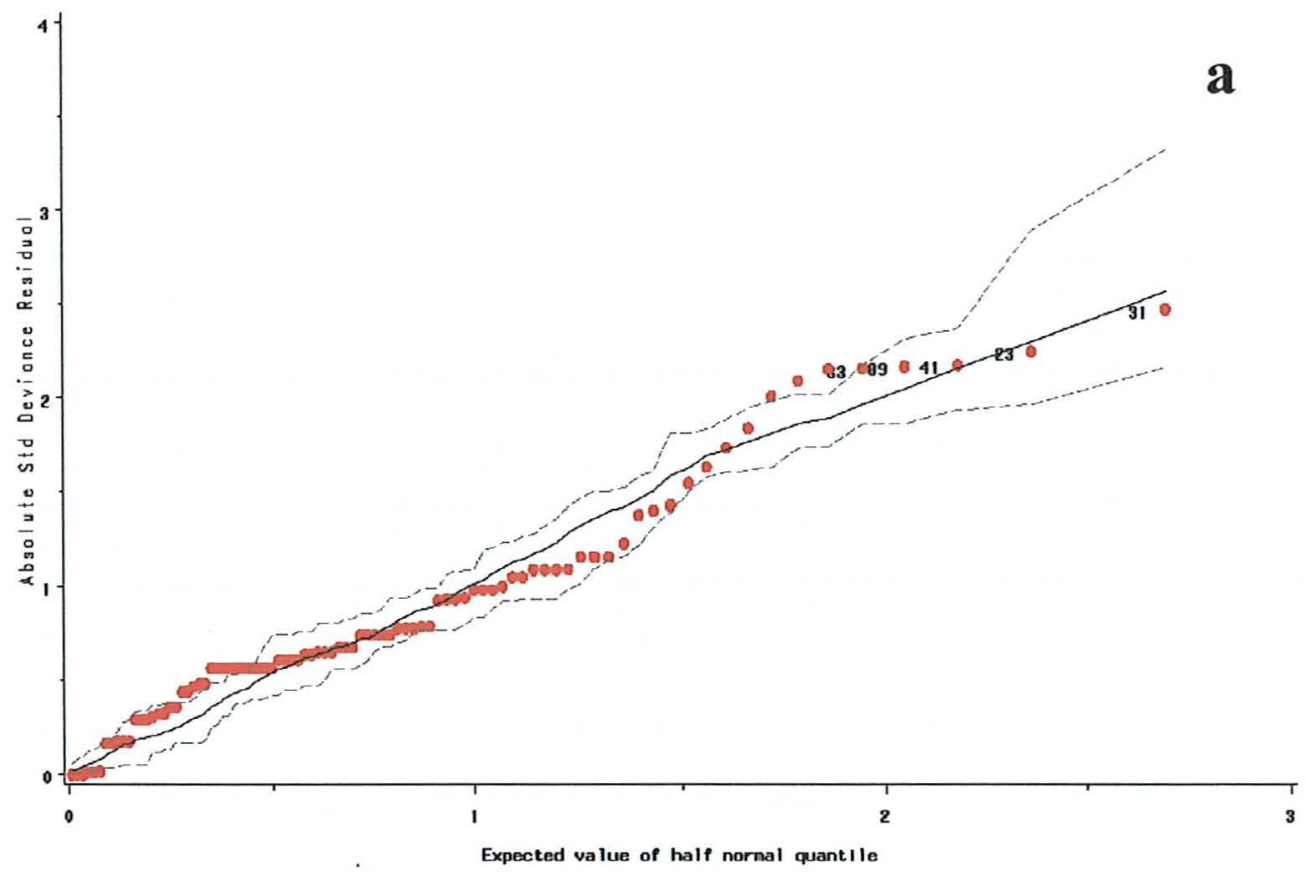

b

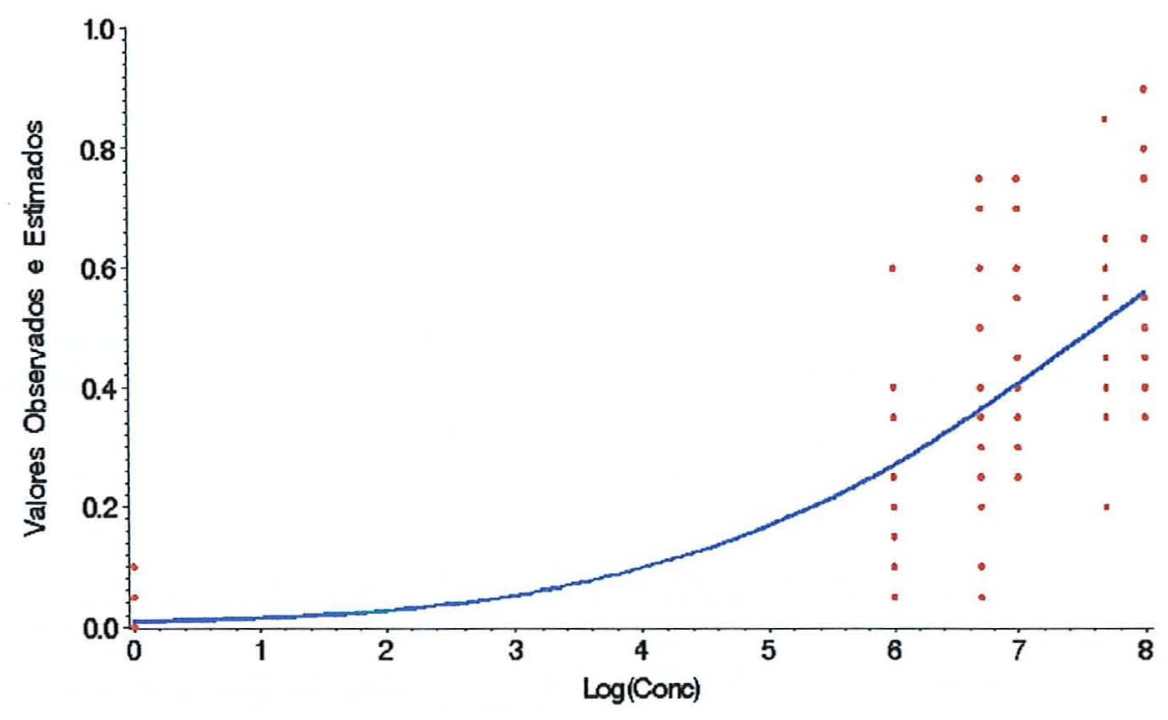

Figura 3 - Proporção de mortalidade de ninfas de $3^{0}$ ínstar de Bemisia tabaci biótipo B, cinco dias após a inoculação com Beauveria bassiana (447) a) valores observados e estimados b) gráfico meio-normal de dados observados em $10^{6}, 5 \times 10^{6}, 10^{7}, 5 \times 10^{7}$ e $10^{8}$ conídios $/ \mathrm{mL}$ $\left(25 \pm 0,5^{\circ} \mathrm{C}, 80 \pm 5 \%\right.$ UR e 12 horas de fotofase). 
Para o isolado 447 , testado nas concentrações de $10^{6}, 5 \times 10^{6}, 10^{7}, 5 \times 10^{7}$ e $10^{8}$ conídios $/ \mathrm{mL}$, foi necessário utilizar uma concentração de $4,2 \times 10^{7}$ conídios $/ \mathrm{mL}$ para matar pelo menos $50 \%$ da população das ninfas, sendo que para $60,80,90 \%$ esses valores foram de $8,2 \times 10^{7}, 4 \times 10^{8}, 1,5 \times 10^{9}$ conídios $/ \mathrm{mL}$, respectivamente. Nos três últimos casos, a elevada concentração apresenta limitações práticas para sua utilização, como a homogeneização das suspensões e principalmente a mortalidade elevada pode dificultar a separação dos isolados.

O critério para a determinação da concentração utilizada nos testes de seleção de isolados foi a mortalidade confirmada igual ou superior a $80 \%$, até sete dias mantida em câmara úmida. Observou-se para esse mesmo isolado que a capacidade de esporulação do fungo sobre os cadáveres das ninfas foi maior que $95 \%$, quando inoculados com $2,1 \times$ $10^{2}$ conídios $/ \mathrm{mm}^{2}\left(10^{7}\right.$ conídios $\left./ \mathrm{mL}\right)$. A partir desses resultados, utilizou-se uma suspensão com concentração de $10^{7}$ conídios $/ \mathrm{mL}$, para selecionar isolados patogênicos de fungos entomopatogênicos, possibilitando a obtenção de dados para futuros testes de estimativa de $\mathrm{TL}_{50}, \mathrm{CL}_{50}$ entre outros.

\subsubsection{Seleção de isolados de fungos visando ao controle de Bemisia tabaci biótipo B}

Durante a realização dos bioensaios, foi verificada grande quantidade de ninfas aderidas na mesma área da folha, dificultando a individualização das mesmas. Desta forma, optou-se pela utilização de pequenos grupos sobre as folhas de soja. Wraight et al. (1998), também verificaram este fato na seleção de isolados de fungos entomopatogênicos para o controle de B. argentifolii (=B. tabaci biótipo B).

Os isolados utilizados nos ensaios de seleção apresentaram entre 95 a $100 \%$ de viabilidade, quando avaliados após 18 horas da inoculação em meio BDA. Os resultados de mortalidade das ninfas causados pelos 44 isolados distribuídos e analisados separadamente em oito bioensaios contam nas Tabela 2 a 5.

$\mathrm{Na}$ Tabela 2 encontram-se os resultados para o ajuste do modelo binomial padrão. Pode-se observar que existem evidências de superdispersão para todos os bioensaios. 
Tabela 2. "Deviances" residuais do modelo binomial padrão.

\begin{tabular}{ccccccccc}
\hline & \multicolumn{7}{c}{ Bioensaios } \\
\cline { 2 - 9 } & 1 & 2 & 3 & 4 & 5 & 6 & 7 & 8 \\
\hline "Deviances" & 89,06 & 86,67 & 111,36 & 143,94 & 72,12 & 119,67 & 70,63 & 78,55 \\
$\begin{array}{c}\text { Graus de } \\
\text { Liberdade }\end{array}$ & 24 & 28 & 44 & 28 & 24 & 28 & 24 & 28 \\
\hline
\end{tabular}

Usando-se os gráficos do tipo meio-normal com envelope simulado (Hinde \& Demétrio, 1997) foi possível constatar que o modelo com fator de heterogeneidade ajustou-se bem a todos os ensaios. Com base em contrastes de tratamentos dois a dois foram, então, feito testes para agrupamentos $(\alpha=0,05)$ e os resultados estão apresentados na Tabela 3. Os grupos formados de tratamentos constam na Tabela 4.

Tabela 3. Teste $F$ para agrupamento de tratamentos e estimativa do fator de heterogeneidade.

\begin{tabular}{lccccccc}
\hline & Bio 1 & Bio 2 & Bio 3 & Bio 4 & Bio 6 & Bio 7 & Bio 8 \\
\cline { 2 - 7 } Entre & $14,61^{*}$ & $31,31^{*}$ & $69,62^{*}$ & $6,67^{*}$ & $26,03^{*}$ & $31,45^{*}$ & $21,93^{*}$ \\
Grupos & $(1)$ & $(1)$ & $(1)$ & $(2)$ & $(1)$ & $(2)$ & $(2)$ \\
\multirow{2}{*}{ Desvios } & 0,16 & 0,08 & 0,34 & 0,22 & 0,31 & 0,43 & 0,58 \\
& $(4)$ & $(5)$ & $(9)$ & $(4)$ & $(5)$ & $(3)$ & $(4)$ \\
\multirow{2}{*}{ Tratamentos } & $6,75^{*}$ & $9,26^{*}$ & $9,37^{*}$ & $2,89^{*}$ & $4,82^{*}$ & $11,70^{*}$ & $7,77^{*}$ \\
& $(5)$ & $(6)$ & $(10)$ & $(6)$ & $(6)$ & $(5)$ & $(6)$ \\
\multicolumn{1}{c}{$\hat{\phi}$} & 3,33 & 2,67 & 2,32 & 4,75 & 3,86 & 2,62 & 2,40 \\
& $(24)$ & $(28)$ & $(44)$ & $(28)$ & $(28)$ & $(24)$ & $(28)$ \\
\hline
\end{tabular}

* indica significância, ao nível de 5\%. 
Tabela 4. Tratamentos agrupados.

\begin{tabular}{|c|c|c|c|c|}
\hline \multirow{2}{*}{ Bioensaios } & \multicolumn{4}{|c|}{ Grupos } \\
\hline & Grupo 1 & Grupo 2 & Grupo 3 & Grupo 4 \\
\hline 1 & Test., $1261,1200,1125$ & 447,1248 & & \\
\hline 2 & $1252,1250,1255,1246,1195$ & 447,1249 & & \\
\hline \multirow[t]{3}{*}{3} & $1232,1233,1253,1210$ & 447 & & \\
\hline & $1213,1245,972,1219,1211$ & & & \\
\hline & PL61 & & & \\
\hline 4 & Test., 1202, 1240 & 1208, PL63 & 447,1145 & \\
\hline 5 & Test. & 447,1037 & 1197,1207 & E9 \\
\hline 6 & Test. & $\begin{array}{l}\text { PL43, 623, 447, 1104, } \\
908,969\end{array}$ & & \\
\hline 7 & Test. & $866,868,935$ & 447,816 & \\
\hline 8 & Test. & $\begin{array}{l}\text { CB } 114, \text { CB } 130 \\
\text { CB } 148\end{array}$ & $\begin{array}{l}447 \\
\text { CB } 144, \\
\text { CB } 139\end{array}$ & \\
\hline
\end{tabular}

A Tabela 5 apresenta as proporções de mosca-branca mortas observadas e os tratamentos de cada bioensaio. A testemunha dos bioensaios 2 e 3 , foram retiradas da análise, pois interferiam no processo de convergência e seu valor observado é nulo. 
Tabela 5. Valores observados de proporção de mortalidade de ninfas de $3^{0}$ instar de Bemisia tabaci biótipo $\mathrm{B}$, cinco dias após a inoculação com fungos entomopatogênicos $\left(25 \pm 0,5^{\circ} \mathrm{C}, 80 \pm 5 \%\right.$ UR e 12 horas de fotofase).

\begin{tabular}{|c|c|c|c|c|c|c|c|c|c|c|c|c|c|c|c|}
\hline \multicolumn{2}{|c|}{ Bio 1} & \multicolumn{2}{|c|}{ Bio 2} & \multicolumn{2}{|c|}{ Bio 3} & \multicolumn{2}{|c|}{ Bio 4} & \multicolumn{2}{|c|}{ Bio 5} & \multicolumn{2}{|c|}{ Bio 6} & \multicolumn{2}{|c|}{ Bio 7} & \multicolumn{2}{|c|}{ Bio 8} \\
\hline Test. & 0,01 & Test. & 0,00 & Test. & 0,00 & Test. & 0,03 & Test. & 0,02 & Test. & 0,02 & Test. & 0,02 & Test. & 0,03 \\
\hline 1125 & 0,06 & 1195 & 0,02 & 1232 & 0,01 & 1202 & 0,12 & 1207 & 0,25 & PLA3 & 0,36 & 866 & 0,34 & CB148 & 0,13 \\
\hline 1261 & 0,14 & 1246 & 0,04 & 1233 & 0,04 & 1240 & 0,16 & 1197 & 0,26 & 623 & 0,40 & 868 & 0,38 & CB130 & 0,18 \\
\hline 1200 & 0,25 & 1255 & 0,04 & 1253 & 0,05 & 1208 & 0,23 & 447 & 0,59 & 447 & 0,42 & 935 & 0,44 & CB114 & 0,24 \\
\hline 1248 & 0,31 & 1250 & 0,07 & 1210 & 0,08 & PL63 & 0,27 & 1037 & 0,61 & 1104 & 0,50 & 816 & 0,68 & CB139 & 0,36 \\
\hline \multirow[t]{7}{*}{447} & 0,52 & 1252 & 0,12 & 1213 & 0,12 & 1145 & 0,31 & E9 & 0,89 & 908 & 0,54 & 447 & 0,70 & $\mathrm{CB144}$ & 0,48 \\
\hline & & 1249 & 0,25 & 1245 & 0,13 & 447 & 0,50 & & & 969 & 0,59 & & & 447 & 0,53 \\
\hline & & 447 & 0,56 & 972 & 0,13 & & & & & & & & & & \\
\hline & & & & 1219 & 0,14 & & & & & & & & & & \\
\hline & & & & PL061 & 0,16 & & & & & & & & & & \\
\hline & & & & 1211 & 0,16 & & & & & & & & & & \\
\hline & & & & 447 & 0,72 & & & & & & & & & & \\
\hline
\end{tabular}

No primeiro bioensaio os isolados 1248 e 1261 de B. bassiana e 1200 de $P$. fumosoroseus causaram entre 14 a $31 \%$ mortalidade, foram semelhantes ao padrão 447 $(52 \%)$ diferindo significativamente da testemunha e por sua vez os isolados 1261 ( $B$. bassiana) e 1125 de $P$. lilacinus tiveram comportamento igual a testemunha com mortalidades entre 6 e 14\%. No segundo bioensaio, o isolado 1249 (B. bassiana) que causou $25 \%$ de mortalidade foi semelhante ao 447 (B. bassiana) com $56 \%$ de mortalidade, sendo mais patogênico aos demais. Os 1195, 1246, 1255, 1250 e 1252 de (B. bassiana) causaram mortalidades variáveis de 2 a $12 \%$ e não diferiram da testemunha. Dados de mortalidade média obtidos no terceiro bioensaio, mostraram que houve diferença estatística significativa entre o padrão 447 (B. bassiana) que provocou $72 \%$ de mortalidade em $B$. tabaci e os isolados 1211, 1219, 1213, 1245, 1210, PL61 (B. bassiana), 972 (V. lecanii), 1233 (Beauveria sp.), 1253 e 1232 (Paecilomyces sp.) que causaram mortalidades variáveis entre 1 e $16 \%$. Todos os isolados tiveram 
comportamento semelhante e não diferiram da testemunha, sendo considerados pouco patogênicos para as ninfas. No quarto experimento a porcentagem média de mortalidade do isolado padrão 447 (B. bassiana) foi de 50\%, enquanto que os demais isolados 1145 (P. lilacinus), 1240, PL63, 1202 e 1208 de (B. bassiana) apresentaram o mesmo comportamento observado na testemunha com mortalidades variando entre 12 a $31 \%$ (Tabela 5).

No quinto experimento não houve diferença significativa entre os isolados $1037 \mathrm{e}$ E9 de $M$. anisopliae (61 e $89 \%$ de mortalidade) e o padrão B. bassiana (447). Os isolados 1207 e 1197 de B. bassiana causaram mortalidades de 25 e $26 \%$ diferindo dos isolados de $M$. anisopliae. Todos os tratamentos diferiram da testemunha. No sexto bioensaio, todos os isolados 969 (B. bassiana), 908 (Beauveria sp.), 623 (P. lilacinus), 1104 e PL43 (M. anisopliae) apresentaram comportamento semelhante ao padrão 447. A mortalidade variou de 36 a $59 \%$ entre esses isolados. $O$ fungo $P$. lilacinus patogênico para nematoides, causou $40 \%$ de mortalidade em $B$. tabaci. Todos os tratamentos foram diferentes em relação à testemunha. No sétimo bioensaio o isolado $816 \mathrm{de} M$. anisopliae foi semelhante a $B$. bassiana (447), causando 68 e $70 \%$ de mortalidade. Verificou-se diferença significativa entre os demais isolados 868 (Beauveria sp.), 935 e 866 de $M$. anisopliae e 447 (B. bassiana) e 816 (M. anisopliae) causaram mortalidades entre 34 e $44 \%$ diferindo da testemunha. No oitavo bioensaio, a análise de variância não detectou diferenças estatísticas significativas entre os isolados CB144 (Paecilomyces sp), 447 (B. bassiana), CB139 (Paecilomyces sp) e CB114 (Paecilomyces sp) que causaram mortalidades variáveis de 24 a $53 \%$, sendo que todos esses isolados foram mais patogênicos que a testemunha. $O$ mesmo não ocorreu em relação aos isolados $\mathrm{CB} 130$, CB148 de Paecilomyces os quais não diferiram da testemunha causando 13 e $18 \%$ de mortalidade (Tabela 5).

Em geral os dados de porcentagens de mortalidade variou de 2 a $70 \%$ para $B$. bassiana sendo o isolado 447 o mais patogênico. Observou-se que as ninfas infectadas por $B$. bassiana apresentaram até $72 \%$ de mortalidade, sendo que os demais isolados foram menos eficientes (Tabela 5). A baixa mortalidade causada por esses patógenos podem estar relacionada ao uso de isolados não provenientes de Bemisia spp. Porém, é 
notável a ausência de epizootias naturais em populações da mosca-branca como mencionados por Lacey et al. (1996) e Wraigth et al. (1998). Entretanto, estudos demostraram o significativo potencial do uso de alguns isolados selecionados a partir esse fungo quando aplicado como micoinseticida contra esse inseto em testes de laboratório, casa-de-vegetação e campo (Fransen, 1990a; Lacey et al., 1996).

A menor virulência de alguns isolados de B. bassiana observados nos bioensaios também pode estar relacionada com o processo de infeção e colonização do fungo. Foram observados sintomas e sinais típicos de infeç̧ão causados por $B$. bassiana nos insetos testados (Figura 4a). Foi possivel observar coloração leitosa no tegumento com o posterior aparecimento de cor rosada ou avermelhada em todo o tegumento das ninfas, causada pela oosporina, pigmento rosa com atividade bactericida que tem a função de evitar a proliferação de outros microrganismos dentro do cadáver (Eyal et al., (1994) (Figura 4b). Neste período, ocorreu a morte de cerca de 30\% dos insetos inoculados. Wraigth et al. (1998), também observaram aparecimento da cor rosada no tegumento das ninfas causados por $B$. bassiana, sendo que esse sintoma foi mais evidente sobre as ninfas de $3^{0}$ e $4^{0}$ ínstar de $B$. tabaci biótipo B. Após a morte do inseto ( 96 horas), observou-se a emergência das hifas através das aberturas naturais (região anal, dorsal e espiráculos), recobrindo as ninfas com micélios de cor branco-amarelo ou branco-creme (Figura $4 b$ e $4 c$ ). 

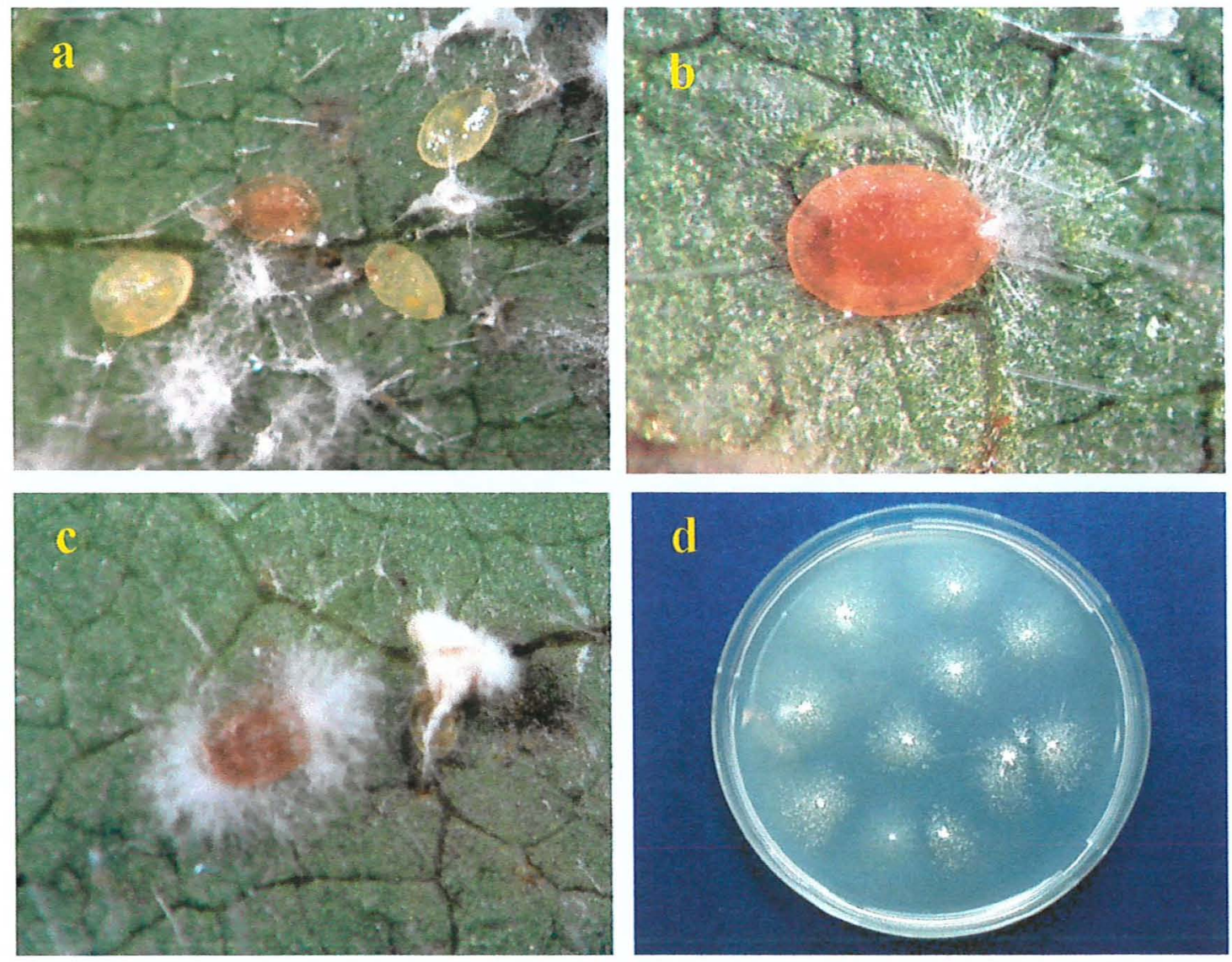

Figura 4 - Ninfas de $3^{0}$ ínstar de Bemisia tabaci biótipo B com sintomas e sinais de Beauveria bassiana a) ninfa sadia e infectada b e c) coloração rosada causada pela oosporina e saída do fungo por aberturas naturais (orifício vasiforme e espiráculos) $50 \mathrm{x}$ e d) confirmação da mortalidade das ninfas em placas com ágar-água $(1,5 \%)\left(25 \pm 0,5^{\circ} \mathrm{C}, 95 \pm 5 \%\right.$ UR e 12 horas de fotofase). 
Para M. anisopliae a mortalidade de B. tabaci variou de 34 a $90 \%$ sendo o isolado E9 o mais patogênico para o inseto. A suscetibilidade das ninfas a isolados $M$. anisopliae foi evidente nos experimentos, sendo essa espécie de fungo promissora para controle de ninfas. Poucos estudos são citados na literatura sobre a ocorrência apizoótica desse patógeno sobre aleirodídeos em campo. O maior valor de porcentagem de mortalidade após cinco dias da inoculação foi de $89 \%$, obtido com o isolado E9 no quinto bioensaio (Tabela 5). A alta virulência do fungo M. anisopliae foi confirmada por Herrera (1995) e Lopes (1999) nos testes de seleção sobre ninfas de mosca-branca e tripes, respectivamente. Com a seleção dessa espécie de fungo, o controle torna-se interessante uma vez que essas pragas ocorrem simultaneamente atacando diversas culturas de interesse agrícola em casa-de-vegetação e campo.

Constatou-se que a partir do terceiro dia após a inoculação obteve-se aproximadamente $30 \%$ de mortalidade, sendo o pico da mortalidade ao quinto dia. Porém, seu efeito rápido no controle de altas populações de Bemisia sp. num curto período de tempo, apresenta uma característica importante e desejável na estratégia de manejo a ser adotada, para espécies de mosca-branca transmissoras de vírus em algumas culturas, como é o caso do biótipo B, tornando-se necessário o controle imediato da praga (Hilje et al., 1998).

Após a adesão, germinação, penetração, colonização e reprodução do patógeno na superfície da cutícula das ninfas tratadas com os isolados de $M$. anisopliae, os insetos apresentaram o tegumento flácido e com pigmentação leitosa, provocada provavelmente pelos metabólitos secundários como as destruxinas produzidas por esses fungos. Estes metabólitos diminuem a resposta imunológica das células do hospedeiro, estas características são semelhantes às descritas por Vestergaard et al. (1999) em relação a esse patógeno. Após a colonização total das ninfas pelo fungo, os insetos infectados tonaram-se duros e cobertos por uma camada pulverulenta de conídios.

A patogenicidade variável de $B$. bassiana e $M$. anisopliae descritas anteriormente sobre as ninfas podem ser atribuídas a muitos fatores, como a variabilidade genética das linhagens, produção de enzimas, toxinas, aderência, velocidade de germinação dos conídios e conseqüente penetração na cutícula das ninfas e capacidade de colonização 
dos isolados (Kleespies \& Zimmermann, 1994). Também, existem estudos que provaram que o armazenamento de blastósporos de $M$. anisopliae afeta sua viabilidade repercutindo na virulência desse patógeno (James, \& Jaronski, 2000).

Uma característica favorável dos isolados E9 e 1037 (M. anisopliae) e 447 ( $B$. bassiana) é a habilidade de crescimento e esporulação em meio de cultura artificial e meio sólido (substrato de arroz pré-cozido) possibilitando sua produção e desenvolvimento comercial. Esses isolados são utilizados como inóculo por empresas privadas no Brasil. Dessa maneira existe a possibilidade que essas espécies de fungos possam ser viáveis no controle de aleirodídeos. Na presente pesquisa, os testes realizados não foram específicos ao modo de ação dos fungos contra as ninfas, porém, foram feitos testes preliminares de Microscopía Eletrônica de Varredura de Pressão Variável (MEV), constatando-se a aderência e esporulação dos conídios de B. bassiana e M. anisopliae sobre a superficie da cutícula das ninfas (Figura 5). 

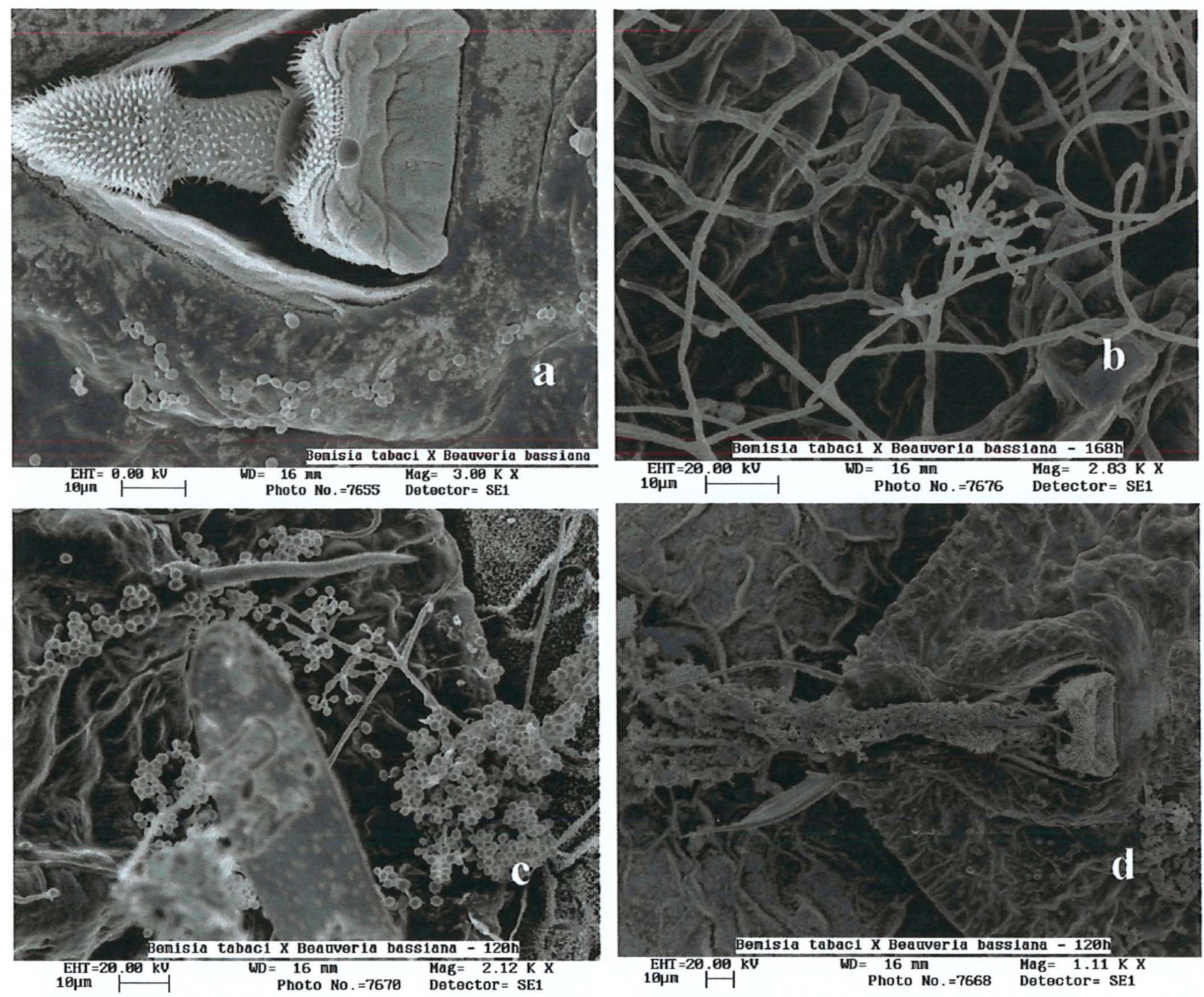

Figura 5 - Fases de desenvolvimento de Beauveria bassiana sobre ninfa de $3^{0}$ ínstar de Bemisia tabaci biótipo $\mathrm{B}$ a) adesão de conídios de Beauveria bassiana sobre a cutícula, $12 \mathrm{~h}$ após a inoculação b) conídio com hifas de Beauveria bassiana na cutícula da ninfa c) colonização da cutícula e produção de conídios de Beauveria bassiana, região dorsal da ninfa d) saída de Beauveria bassiana pelo orifício vasiforme após a colonização na hemocele da ninfa, $120 \mathrm{~h}$ (MEV). 
Para espécies de Paecilomyces a mortalidade de $B$. tabaci variou de 1 a $45 \%$ sendo que $P$. lilacinus (isolado 623) causou 40\% de mortalidade. O isolados 972 de $V$. lecanii, único testado provocou apenas $13 \%$ de mortalidade nas ninfas. Os isolados de $P$. fumosoroseus e $P$. lilacinus foram pouco patogênicos para ninfas, apresentando índices baixos de mortalidade, que não ultrapassaram $48 \%$. Observou-se que as ninfas foram rapidamente infectadas e mortas. A suscetibilidade de adultos, ninfas e ovos de $B$. argentifolii ao fungo $P$. amoenesoroseus foi avaliada por Candido (1999) onde a mortalidade média de adultos chegou a $67 \%$, enquanto que para ovos e ninfas os valores foram de 4,1 e 9, respectivamente. O mesmo autor mencionou que a velocidade de mortalidade provocada por este fungo sobre insetos adultos foi similar àquela provocada por $B$. bassiana e $P$. fomosoroseus. Landa et al. (1994) mencionaram que esses patógenos infectam todos os estágios ninfais de aleirodídeos. No entanto, Lacey et al. (1996) consideraram que ambas espécies de fungos foram mais efetivas para adultos que para ninfas e ovos. Testes utilizando $P$. fumosoroseus e $B$. bassiana mostraram a capacidade desses fungos em infectar ninfas de $3^{0}$ instar de $B$. argentifolii quando inoculados com 50 a 150 conídios $/ \mathrm{mm}^{2}$ e incubados a $25 \% \mathrm{UR}, 23 \pm 2^{\circ} \mathrm{C}, 16$ horas de fotofase (Wraight et al., 1998). Testes de seleção com um número maior de isolados de $P$. fomosoroseus, especialmente $P$. farinosus são importantes, já que são encontrados naturalmente no agroecossistema causando epizootias em populações da mosca-branca (Lacey et al., 1996; Vidal et al., 1997; Wraight et al., 1998).

Foram observados sintomas e sinais de infecção de Paecilomyces spp. nas ninfas, as quais caracterizaram-se pela coloração amarelada a laranja, mais intensa por ocasião da conidiogênese total, sobre os cadáveres das mesmas. Wraight et al. (1998) observaram os mesmos sintomas e sinais de infeção por esse fungo além de verificar que $P$. fomusoroseus inicialmente emerge pela região anal (orificio vasiforme) do hospedeiro morto e, freqüentemente, o cadáver é coberto com o crescimento rápido das hifas e esporulação dos conídios.

A infecção de $P$. fumosoroseus nos estágios ninfais foi observada 24 horas após a penetração na cutícula. Esta característica foi apresentada pelos isolados CB144 e CB139 de Paecilomyces spp., isolados 623, 1145, 1125 de P. lilacinus, 1200 de $P$. 
fumosoroseus e 972 de $V$. lecanii. Estudos de microscopia realizados por Osborne et al. (1990) constataram que Paecilomyces spp. atacaram a parte dorsal do inseto onde ocorre a formação de tubos germinativos, que penetraram na hemocele em 24 horas. Os micélios emergiram do interior do corpo das ninfas em 48 horas e a esporulação ocorreu em 72 horas.

Assim, os resultados dos bioensaios foram diferentes em relação a patogenicidade contra as ninfas de B. tabaci sendo a espécie de Metarhizium mais patogênico seguido de Beauveria, Paecilomyces e Verticillium. Resultados similares sobre o mesmo inseto e com as mesmas espécies de fungos foram também conseguidos por Hererra (1995).

Neste estudo, não foi relacionada patogenicidade com a procedência dos mesmos, sendo que nenhuma das linhagens utilizadas nos testes foram coletadas e isoladas de mosca-branca. De acordo com Vestergaard et al. (1995) a patogenicidade independe do hospedeiro ou local de origem do isolado. A baixa porcentagem de mortalidade verificada em cada bioensaio pode estar relacionada a variabilidade genética de cada isolado, sendo que a maioria dos isolados de fungos anteriormente mencionados, foram pouco patogênicos para as ninfas do biótipo $B$.

As diferenças de patogenicidade dos isolados podem ser devidas a vários fatores sendo que a virulência de um determinado isolado pode estar relacionada com a velocidade de germinação e consequentemente penetração na cutícula do inseto. Alves et al. (1996) verificaram que diferentes condições de armazenamento influenciaram a velocidade de germinação dos conídios de $B$. bassiana e consequentemente na virulência do patógeno para Diatraea saccharalis. Especula-se que as etapas seguintes após a aderência e germinação do fungo sobre a ninfa, durante a penetração da cutícula o patógeno, poderia ser atingido por condições adversas afetando o crescimento micelial dentro do inseto e a esporulação na superficie do cadáver infectado (Smith \& Grula, 1981).

O tegumento é importante no processo de infecção do fungo porque consiste em uma barreira física para a penetração do tubo germinativo, complementando-se com as propriedades químicas que provavelmente inibem a germinação do conídio. Por outro 
lado, possuem também fontes de nutrientes para alguns fungos (Smith \& Grula, 1981; Alves, et al., 1986). No caso de ninfas de mosca-branca, a cutícula produz lipídeos e especialmente os de longas cadeias de ésteres de cêra, sendo que essas camadas espessas são uma barreira física para os conídios, prejudicando dessa maneira a adesão, germinação e penetração (Buckner et al., 1999). A redução da germinação dos conídios sobre a cutícula das ninfas poderia ser devido a insuficiente quantidade de nutrientes afetando a germinação de $B$. bassiana (James, 2001). No $3^{0}$ ínstar o inseto ainda é capaz de produzir cêra, além de apresentar maior suscetibilidade desse ínstar como confirmado por Osborne \& Landa (1992) e Serra (1996).

Após repetidos bioensaios usando isolados de fungos selecionados contra as ninfas da mosca-branca deve ser considerada a manutenção da patogenicidade $e$ virulência desses patógenos. Uma forma para se manter essas características seria mediante a passagem pela cutícula e re-isolamento do fungo obtido nos cadáveres infectados. A produção de conídios evidencia a capacidade do patógeno em completar todo o ciclo dentro do hospedeiro. Para trabalhos envolvendo ninfas desse inseto seria interessante que esses testes fossem realizados antes e após os ensaios de patogenicidade para garantir a virulência desses microrganismos (Vidal et al., 1997; Brownbridge et al., 2001).

Os resultados referentes a mortalidade corrigida e confirmada no quinto dia após a inoculação estão representados graficamente na Figura 6. A avaliação da porcentagem de mortalidade confirmada baseada na esporulação desses microrganismos sobre as ninfas facilitou as avaliações (Figura 1d), além de revelar a capacidade patogênica do fungo e mostrar o potencial de conidiogênese, que é um fator determinante na disseminação do patógeno entre indivíduos da população de mosca-branca como também para outras pragas presentes no mesmo local. A maioria dos isolados (mais de 95\%) apresentaram confirmação da infecção causada pelos fungos. 


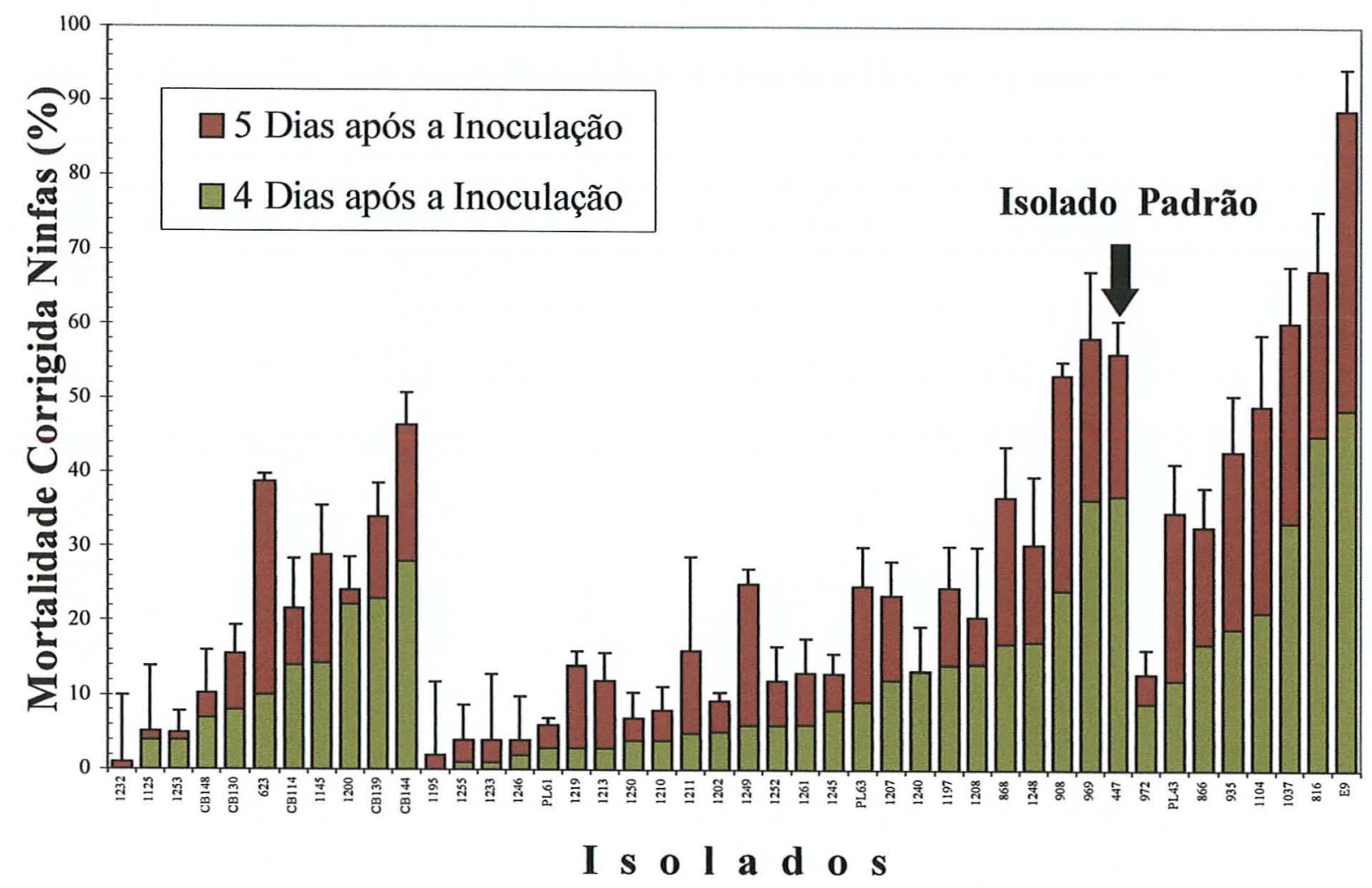

Figura 6 - Mortalidade corrigida e confirmada de ninfas de $3^{\underline{0}}$ ínstar de Bemisa tabaci biótipo $\mathrm{B}$ com fungos entomopatogênicos, cinco dias após a inoculação $\left(25 \pm 0,5^{\circ} \mathrm{C}, 80 \pm 5 \%\right.$ UR e 12 horas de fotofase). 
Para se desenvolver um produto microbiano há necessidade de estudar e desenvolver as fases propostas por Alves et al. (1998). Assim, estudos aqui elaborados constituem apenas a fase inicial do desenvolvimento de um produto para o controle da mosca-branca com fungos entomopatogênicos. Foram selecionados alguns isolados promissores como primeira medida, possibilitando dessa maneira o estudo de outras fases importantes como caracterização das linhagens, desenvolvimento de uma formulação, testes de eficiência em laboratório, casa-de-vegetação e campo, desenvolvimento de estratégias de aplicação e produção comercial, sendo primordiais para esse fim. Alem disso, as espécies de fungos selecionadas também devem atuar sobre outras pragas que ocorrem num mesmo ambiente causando perdas econômicas nas culturas de interesse agrícola. 


\section{CONCLUSÕES}

- Todos os isolados testados de Beauveria bassiana, Metarhizium anisopliae, Paecilomyces fumosoroseus, Verticillium spp. são patogênicos para $B$. tabaci biótipo $\mathrm{B}$.

- Os isolados E9, 1037, 816 de Metarhizium anisopliae e o isolado 447 e 969 de Beauveria bassiana são promissores para o desenvolvimento de inseticidas microbianos visando o controle de B. tabaci biótipo B. 


\section{REFERÊNCIAS BIBLIOGRÁFICAS}

ABBOTT, W.S. A method of computing the effectiveness of an inseticide. Journal of Economic Entomolology, v.18, p.265-267, 1925.

ALVES, S.B. Fungos entomopatogênicos. In: ALVES, S.B. (Ed.). Controle microbiano de insetos. São Paulo: FEALQ, 1986. cap.11, p.73-126.

ALVES, S.B. Fungos entomopatogênicos. In: ALVES, S.B. (Ed.). Controle microbiano de insetos. 2.ed. São Paulo: FEALQ, 1998. cap.11, p.289-381.

ALVES, S.B.; PEREIRA, R.M.; STIMAC, J.L.; VIEIRA, S.A. Delayed germinação of Beauveria bassiana conidia after prolonged storage at low, above-freezing temperatures. Biocontrol Science and Technology, v.6, p.575-581, 1996.

ANDREI, E. Compêndio de defensivos agrícolas. 6.ed. São Paulo: Organização Andrei, 1999. 672p.

BELLOWS Jr., T.S.; PERRING, T.M.; GILL, R.; HEADRICK, D.H. Description os of a species of Bemisia (Homoptera: Aleyrodidae). Annals of the Entomological Society of America, v.37, n.2, p.195-206, 1994.

BETHKE, J.; REDAK, R. Effect of imidacloroprid on the silverleaf whitefly, Bemisia argentifolii bellows and perring (Homoptera: Aleyrodidae) and whitefly parasitism. Annals of Applied Biology, v.130, p.397-407, 1997. 
BETHKE, J.A.; PAINE, T.D.; NUESSLY, G.S. Comparative biology, morphometrics, and development of two populations of Bemisia tabaci (Homopetra: Aleyrodidade) on cotton and poinsettia. Annals of the Entomological Society of America, v.84, p.407-411, 1991.

BIOBEST. Products biological control: Encarsia system. http://www.biobest.be/sp/productten/nuttig/encarsia.htm (24 ago. 2001a).

BIOBEST. Products biological control: Delphastus system. http://www.biobest.be/sp/producten/muttig/delphastus.htm (24 ago. 2001b).

BIOBEST. Biological control: Biopeticides Paecilomyces fomosoroseus. http:www.biobest.be/sp/index.htm (22 ago.2001c).

BRODSGAARD, H.F. "Keep down", a concept of trips biological control in ornamental pot plants. In: PARKER, B.L.; SKINNER, M. LEWIS, T. Trips biology and management. New York: Plenum Press, 1995. p.221-224.

BROWN, J.K.; BIRD, J. Whitefly-transmitted geminivirus and associated disorders in the Americas and the Caribbean Basin. Plant Disease, v.76, n.3, p.220-225, 1992.

BROWN, J.K.; GROHLICH, D.R.; ROSELL, R.C. The sweetpotato or silverleaf whiteflies: biotypes of Bemisia tabaci or a species complex?. Annual Review of Entomology, v.40, p.511-534, 1995.

BROWNBRIDGE, M.; COSTA, S.; JARONSKI, S. Effects of in vitro passage of Beauveria bassiana on virulence to Bemisia argentifolii. Journal of Invertebrate Pathology, v.77, p.280-283, 2001. 
BUCKNER, J.S.; HAGEN, M.M.; NELSON, D.R. The composition of the cuticular lipids from nymphs and exuviae of the silverleaf whitefly Bemisia argentifolii. Journal Comparative Biochemistry and Physiology. B. Biochemistry \& Molecular Biology, v.124, p.201-207, 1999.

BYRNE, D.N.; BELLOWS JUNIOR, T.S. Whitefly biology. Annual Review of Entomology, v.36, p.431-457, 1991.

CABALlERO, R. Identificación de moscas blancas. In: HILJE, L. (Ed.). Metodologias para el estudio y manejo de moscas blancas y geminivirus. Turrialba: CATIE, 1996. cap.1, p.1-10.

CANDIDO, G.F.O. Virulence of the entomopathogenic fungus Paecilomyces amoeneroseus (Hennings) Samson toward the whitefly Bemisia argentifolii bellows and perring. Riverside, 1999. 100p. Thesis (Ph.D.) - University of California.

CARAZO, E.; MARTÍNEZ, J.L.; BUSTAMANTE, M. Inseticidas y resistencia. In: HILJE, L. (Ed.). Metodologias para el estudio y manejo de moscas blancas y geminivirus. Turrialba: CATIE, 1996. cap.10, p.84, 96-10.

CARVER, M.; GROSS G.F.; WOODWARD, T.E. Hemiptera (bugs, leafhoppers, cicadas, aphids, scale insects, etc.). In: NAUMANN, I.D. (Ed.). Systematic and applied entomology: an introdution. Melbourne: Melbourne University Press, 1994. cap.30, p.316-329.

CAVE, R.D. Es viable el control biológico de un vector de geminivirus, como Bemisia tabaci?. Manejo Integrado de Plagas, n.34, p. 18-22, 1994.

COSTA, C.L. Vetores de vírus de plantas Revisão Anual de Patologia de Plantas, v.6, p.133-134, 1998. 
DEMÉTRIO, C.G.B.; HINDE, J.P. Half-normal plots and overdispersion. GLIM Newsletter, v.27, p.19-26, 1997.

EKBOM, B.S. Humidity requeriments and storage of the entomopatogenic fungus Verticillium lecanii for use in glasshouse. Annales Entomologici Fennici, v.47, p.61-62, 1981 .

EYAL, J.; MABUD, M.D.A.; FISCHBEIN,K.L.;WALTER,J.F; OSBORNE,L.S.; LANDA, Z. Assessment of Beauveria bassiana Nov. EO-1 strain, wich produces a red pigment for microbial control. Applied Biochemistry and Biotechnology, v.44, p.65-80, 1994.

FERRON, P. Biological control of insect pest by entomogenous fungi. Annual Review of Entomology, v.23 p.409, 1978.

FRANÇA, F.H.; VILLAS BÔAS, G.L; BRANCO, M.C. Ocorrência de Bemisia argentifolii Bellows \& Perring (Homoptera:Aleyrodidae) no Distrito Federal. Anais da Sociedade Entomológica do Brasil, v.25, n.2, p.369-372, 1996.

FRANSEN, J.J. Fungi of aphids, thrips and whitefly in the greenhouse environment. In: INTERNATIONAL COLLOQUIUM ON INVERTABRATE PATHOLOGY AND MICROBIAL CONTROL, 5., Adelaide, 1990. Proceedings. Adelaide: Society for Invertebrate Pathology, 1990a. p.376-380.

FRANSEN, J.J. Natural enemies of whiteflies: fungi. In: GERLING, D. (Ed.) Whiteflies: their bionomics, pest status and management. Andover: Intercept, 1990b. cap. 8 , p. 187-210. 
FRANSEN, J.J.; WINKELMAN, K.; VAN LENTERN, J.C. The differential mortality at various life stages of the greenhouse whitefly, Trialeurodes vaporariorum (Homoptera: Aleyrodidae), by infection with the fungus Aschersonia aleyrodis (Deuteromycotina: Coelomycetes). Journal of Invertebrate Pathology, v.50, p.158-165, 1987.

FUNK, J.; HUNTER, W.B.; ACHOR, D.S. Replication of insect Iridescent Virus 6 in a whitefly cell line. Journal of Invertebrate Pathology, v.77, p. 144-146, 2001.

GARCIA-GONZÁLVES, L.; LÓPEZ-ÁVILA, A. Evaluación de cepas nativas de Verticillium lecanii (Zímm.) viegas en el control de la mosca blanca de los invernaderos Trialeurodes vaporariorum (Westwood). Revista Colombiana de Entomologia, v.23, p.25-30, 1997.

GAWEL, N.J; BARTLETT, A.C. Characterization of differences between whiteflies using RAPD-PCR. Insect Molecular Biology, v.2 p.33-38, 1993.

GERLING, D. Status of Bemisia tabaci in the mediterranean countries: opportunities for biological control. Biological Control, v.6, p.11-22, 1996.

GILLESPIE, A.T.; CLAYDON, N. The use of entomogenous fungi for pest control and the role of toxins in pathogenesis. Pesticide Science, v.27, p.203-215, 1989.

GINDIN,G.; BEM-ZE'EV, I.S. Natural occurrence of and inoculation experiments with Conidiobolus coronatus and Conidiobulos sp. in glasshouse populations of Bemisia tabaci. Phytoparasitica, v.22, 197-208, 1994. 
HALL, A.; PETERKING, D. ALI, B. Fungal control of whitefly, Trips palmi and sugarcane froghopper in Trinidad and Tobago. In: ANNUAL MEETING OF THE SOCIETY FOR INVERTEBRATE PATHOLOGY AND MICROBIAL CONTROL, 26., Montpellier, 1994. Proceedings. Trinidad Tobago: Society for Invertebrate Pathology, 1994. p.277-282.

HEALE, J.B. The potencial impact of fungal genetic and molecular biology on biological control, with particular reference to entomopathogens. In: BURGE, M.N. (Ed.). Fungi in biological control systems. Manchester: University Press, 1988. p.211-234.

HEINZ, K.M.; BRAZZLE, J.R.; PARRELLA, M.P.; PICKETT, C.H. Field evaluations of aumentative releases of Delphastus catalinae (Horn) (Coleoptera: Coccinellidae) for suppression of Bemisia argentifolii Bellows \& Perring (Homoptera: Aleyrodidae) infesting cotton. Biological Control, v.16, p.241-251, 1999.

HERRERA, F.J. Evaluación de hongos entomopatogènicos para el control microbiano de Bemisia tabaci (HOMOPTERA: ALEYRODIADE). Turrialba, Costa Rica, 1995. 69p. Tesis (M.S.) - Centro Agronómico Tropical de Investigación y Enseñanza.

HINDE, J.P.; DEMÉTRIO, C.G.B. Overdispersion: models and estimation. Computation Statistics and Data Analysis, v.27, p.151-170, 1998.

HILJE, L. Un modelo de colaboraçión agrícola internacional para el manejo de moscas blancas y geminivirus en America Latina y el Caribe: a model of internacional agricultural collaboration for whitefly and geminivirus managent in Latin América and Caribeen. Manejo Integrado de Plagas, n.49, p.1-9, 1998. 
HODDLE, M.S.; VAN DRIESCHE R.G.; SANDERSON, J.P.; MINKENBERG, O.P.J.M. Biological control of Bemisia argentifolii (Hemiptera: Aleyrodidae) on poinsettia with inundative releases of Eretmocerus eremicus (Hymenoptera: Aphelinidae): do release rates affect parasitism?. Bulletin of Entomological Research, v.88, p.47-58, 1998.

JAMES, R.R. Effects exogenous nutrients on conidial germination and virulence against the silverleaf whitefly for two hyphomycetes. Journal of Invertebrate Pathology, v.77, p.99-107, 2001.

JAMES, R.R.; JARONSKI, S.T. Effect of low viability on infectivity of Beauveria bassiana conidia toward the silverleaf whitefly. Journal of Invertebrate Pathology, v.76, p.227-228, 2000 .

KERSHAW, M.J.; MOORHOUSE, E.R.; BATEMAN, R.; REYNOLDS, S.E.; CHARNLEY, A.K. The role of destruxins in the pathogenicity of Metarhizium anisopliae for three species of insect. Journal of Invertebrate Pathology, v.74, p.213-223, 1999.

KLEESPIES, R.G.; ZIMMERMANN, G. Effect of additives on the prodution, viability and virulence of blastospores of Metarhizium anisopliae. Biocontrol Science and Technology, v.4, p.309-319, 1994.

KOOPERT. Pest control: EN-STRIP, ENERMIX e ERCAL.

http://www. koppert.n1/cgi-bin/x0210.pl?lang=\&kpgr sreID=2 (22 ago. 2001a).

KOOPERT. Pest control: Mycotal Verticillium lecanii (entomopathogenic fungus).

http://www.koopert.nl/cgi-bin/x031.pl?ktrnsrcID=5\&lang=e (27 ago. 2001b) 
LACEY, L.A.; FRANSEN, J.J.; CARRUTHERS, R.I. Global distribution of naturally occurring fungi of Bemisia, their biologies and use as biological control agents. In:

GERLING, D.; MAYER, R.T. (Ed.). Bemisia 1995: taxonomy, biology, damage, control and management. Andover: Intercept, 1996. p. 356-456.

LANDA, Z.; OSBORNE, L.; LOPEZ, F.; EYAL, J. A biossay for determining pathogenicity of entomogenous fungy on whitefly. Biological Control, v.4, p.341350, 1994.

LASTRA, R. Los geminivirus un grupo de fitovirus com características especiales. In: MEMORIAS DEL TALLER CENTROAMERICANO Y DEL CARIBE, Turrilaba, 1993. Las moscas blancas (Homoptera: Aleyrodidae) en América Central y el Caribe. Turrialba: CATIE, 1993. p.16-19.

LOPES, R.B. Seleção de fungos entomopatogênico e controle de Frankliniella occidentalis. (Tysanoptera: Thripidae). Piracicaba, 1999. 72p. Dissertacão (Mestrado) - Escola Superior de Agricultura "Luiz de Queiroz", Universidade de São Paulo.

LOURENÇÃO, A.L.; NAGAI, H. Surtos populacionais de Bemisia tabaci no estado de São Paulo. Bragantia, v.53, p.53-59, 1994.

LOURENÇÃO, A.L.; MIRANDA, M. A.; ALVES, S.B. Ocorrência epizoótica de Verticillium lecanii em Bemisia tabaci biótipo B (Hemiptera: Aleyrodidae) no Estado do Maranhão. Neotropical Entomology, v.30, n.1, p.183-185, 2001.

MEADE, D.L.; BYRNE, D.N. The use of Verticillium lecanii against subimaginal instar of Bemisia tabaci. Journal of Invertebrate Pathology, v.57, p.296-298, 1991. 
MIER, T.; RIVERA, BERMÚDEZ, J.; DOMÍNGUEZ, Y.; BENAVIDES, C.; ULLÓA, M. Primer reporte en México del aislamiento de Verticillium lecanii a partir de la mosquita blanca y pruebas de patogenecidad in vitro sobre este insecto. Revista Mexicana de Micología, v.7, p.149-165, 1991.

MILNER, R.J.; LUTTON, G.G. Dependence of Verticillium lecanii (Fungi: Hyphomycetes) on high humidities for infection and sporulation using Myzus persicae (Homoptera: Aphididae) as host. Enviromental Entomology, v.15, p.380-382, 1986.

MYCOTECH. Agriculture: Mycotrol mycoinseticide.

http://www.mycotech.com/products/mycotrol.shtml (22 ago. 2001a).

MYCOTECH. Greenhouse \& Nursery BotaniGard 22WP Mycoinseticide. http://www. mycotech.com/horticulture/botanigard22wp.shtml. (22 ago. 2001b).

NELDER, J.A.; WEDDERBURN, R.W.M. Generalized linear models. Journal of the Royal Statistical Society. Series A, v.135, p.370-384, 1972.

ORTEGA-ARENAS, L.D. Resistencia de Bemisia argentifolii a inseticidas: implicaciones y estratégias de manejo em México. Manejo Integrado de Plagas, n. 49, p. 10-25, 1998 .

OSBORNE, L.S.; LANDA, Z. Biological control Of whiteflies with entomopathogenic fungi. Florida Entomology, v.75, 456-471, 1992. 
OSBORNE, L.S.; STOREY G.K.; MCCOY C.W.; WALTER, J.F. Potential for controlling the sweetpotato whitefly, Bemisia tabaci, with the fungus, Paecilomyces fumosoroseus. In: INTERNATIONAL COLLOQUIUM ON INVERTEBRATE PATHOLOGY AND MICROBIAL CONTROL, 5., Adelaide, 1990. Proceedings. Adelaide: Society for Invertebrate Pathology, 1990. p.386-390.

PERRING, T. M.; COOPER, A.; KAZMER, D.J. Identification of the poinsettia strain of Bemisia tabaci (Homoptera: Aleyrodidae) on broccoli by electrophoresis. Journal of Economic Entomology, v.85, p.1278-1284, 1992.

RAMOS, E.Q. Susceptibilidad de Bemisia tabaci a Beauveria bassiana em condiciones de laboratorio. Manejo Integrado de Plagas, n.56, p.65-69, 2000.

ROMBACH, M.C.; GILLESPIE, A.T. Entomogenous hyphomycetes for insect and mite control on greenhouse crops. Biocontrol News and Information, v.9, n.1, p.7-18, 1988.

RYLEY, D.G.; CIOMPERLIK, M. A. Regional population dynamics of whitefly (Homoptera: Aleyrodidae) and associated parasitoids (Hymenoptera: Aphelinidae). Population Ecology, v.26, n.5, p.1049-1055, 1997.

SAS INSTITUTE. SAS/STAT: user's guide, version 8. Cary, 1999. 846p.

SERRA, C.A. Biologia de moscas blancas. In: HILJE, L. (Ed.). Metodologias para el estudio y manejo de moscas blancas y geminivirus. Turrialba: CATIE, 1996. cap. 2, p.11-21.

SHANNON, P.S. Hongos entomopatógenos. In: HILJE, L. (Ed.). Metodologias para el estudio y manejo de moscas blancas y geminivirus. Turrialba: CATIE, 1996. cap.7, p.60-68. 
SIMMONS, A. M. Oviposition on vegetables by Bemisia tabaci, (Homoptera: Aleyrodidae): temporal and leaf surfase factors. Enviromental Entomology, v.32, p.382-389, 1994.

SIMMONS, A. M.; JACKSON D.M. Evaluation of foliar-applied inseticides on abundance of parasitoids of Bemisia argentifolii (Homoptera: Aleirodidae) in vegetables. Journal of Entomological Science, v.35,n.1, p.1-8, 2000.

SMITH, R.J.; GRULA, E.A. Nutritional requirements for conidial germination and hyphal growth of Beauveria bassiana. Journal of Invertebrate Pathology, v.37, p. 222-230, 1981.

TANADA, Y.; KAYA, H. Fungal infections. In: TANADA, Y.; KAYA, H. (Ed.) Insect pathology. San Diego: Academic Press, 1993. cap.10. p.318-387.

TORRES, S. E.; CÁRDENAS, H.M. Producción y comercialización de hongos entomopatogenicos en Sinaloa. In: CONGRESSO NACIONAL DE CONTROL BIOLOGICO, 19., Sinaloa, 1996. Memorias. Sinaloa: Sociedad Mexicana de Control Biológico, 1996. p.21-22.

VAN LENTEREN, J. Biological control of greenhouse whitefly (Trialeurodes vaporariorum) with the parasitoid Encarsia formosa: how does it work? Biological Control, v.6, p.1-10, 1996.

VAN ROERMUND, H.J.; VAN LENTEREN, J.C.; RABBINGE, R. Biological control of greenhouse whitefly with the parasitoid Encarsia formosa on tomato: an individual-based simulation approach. Biological Control, v.9, 25-47, 1997. 
VEGA, F.E.; JACKSON, M.A.; MCGUIRE,M.R. Germination of conidia blastospores of Paecilomyces fomosoroseus on the cuticule of the silverleaf whitefly, Bemisia argentifolii, Mycopathologia, v.147, p.33-35, 1999.

VEGA, J.B. Manejo de Bemisia tabaci mediante barreras vivas e Paecilomyces en Oaxaca, México. Manejo Integrado de Plaga, n.52, p.80-88, 1999.

VESTERGAARD, S.; BUTT, T.M.S.; BRESCIANI, J.; GLLESPIE, A.T.; EILENBERG, J. Light and electron microscopy studies os the infection of the western flower trips Frankliniella occidentalis (Thysanopter: Thripidae) by the entomopathogenic fungus Metarhizium anisopliae. Journal of Invertebrate Pathology, v.73, p. 25-33, 1999.

VESTERGAARD, S.; GILLESPIE, A.T.; BUTT, T.M; SCHREITER, G.; EILENBERG, J. Pathogenecity of the hyphomycete fungi Verticillium lecanii and Metarhizium anisopliae to the western flower thrips, Frankliniella occidentalis. Biocontrol Science and Technology. v.5, p.185-192, 1995.

VICENTINI, S.; FARIA, M.; OLIVEIRA, R.V.M. de. Screening of Beuaveria bassiana (Deuteromycotina: Hyphomycetes) isolates against nymphs of Bemisia tabaci (Genn.) biotype B (Hemiptera:Aleyrodidae) with description of a bioassay method. Neotropical Entomology, v.30, n.1, p.97-103, 2001.

VIDAL, C.; OSBORNE, L.S.; LACEY, A.L.; FARGUES, J. Effect of host plant on the potential of Paecilomyces fumosoroseus (Deuteromycotina: Hyphomycetes) for controlling the silverleaf whitefly, Bemisia argentifolii (Homoptera: Aleyrodidae) in greenhouses. Biological Control, v.12, p.191-199, 1998. 
VIDAL, C.; LACEY, A.L.; FARGUES, J. Pathogenicity of Paecilomyces fumosoroseus (Deuteromycotina: Hyphomycetes) against Bemisia argentifolii (Homoptera: Aleyrodidae) with a description of a bioassay method. Journal of Economic Entomology, v.90, n.3, p.765-772, 1997.

VISCARRET, M.M.; BOTTO, E.N.; POLASZEK, A. Whiteflies (HEMIPTERA: ALEYRODIADE) of economic importance and their natural enemies (HYMENOPTERA: APHELILINIDAE, SIGNIPHORIDAE) in Argentina. Revista Chilena de Entomologia, v.26, p.5-11, 2000.

WRAIGHT, S.P.; CARRUTHERS, R.I.; BRADLEY, C.A.; JARONSKI, S.T.; LACEY, L.A.; WOOD, S.P.; GALAINI-WRAIGHT, S. Patogenicity of the entomopatogenic fungi Paecilomyces spp. and Beauveria bassiana against the silverleaf whitefly, Bemisia argentifolii. Journal of Invertebrate Pathology, v.71, p.217-226, 1998.

WRAIGHT, S.P.; CARRUTHERS, R.I.; JARONSKI, S.T.; BRADLEY, C.A.; GARZA, C.J.; GALAINI-WRAIGHT, S. Evaluation of the entomopatogenic fungi Beauveria bassiana and Paecilomyces fumosoroseus for microbial control of the silverleaf whitefly, Bemisia argentifolii. Biological Control, n.17, p 203-217, 2000.

ZAKI, F.N. Efficiency of the entomopathogenic fungus, Beauveria bassiana (Bals), against Aphis crassivora Koch and Bemisia tabaci. Journal of Applied Entomology, v. 122, p.397-399, 1998.

ZIMMERMANN, G. The entomopathogenic fungus Metarhizium anisopliae and its potential as a biocontrol agent. Pesticide Science, v.37, p.375-379, 1993. 